\title{
"LO QUE QUEREMOS ES QUE SALGAN LOS BLANCOS Y LAS TROPAS”. YAQUIS Y MEXICANOS EN TIEMPOS DE REVOLUCIÓN (1910-1920)
}

\author{
Nicolás Cárdenas García \\ Universidad Autónoma Metropolitana-Xochimilco
}

Ta consolidación del porfiriato en Sonora tuvo conseLuencias de largo alcance para el pueblo yaqui, ya que en ese periodo dio inicio un proyecto modernizador de las autoridades, tanto estatales como federales, para colonizar y hacer productivas las ricas tierras del valle que habitaban. Tal proyecto, como ha sido relatado por varios estudiosos, encontró una decidida resistencia y tuvo que ser respaldado por una larga guerra en la que el ejército federal usó todos los medios a su alcance, incluyendo la deportación de miles de yaquis al sureste del país. ${ }^{1}$

Por el lado del pueblo yaqui, tenemos evidencia de respuestas más bien entremezcladas a esta política. Si bien la nación yaqui había conservado una notable unidad territorial

Fecha de recepción: 2 de noviembre de 2015

Fecha de aceptación: 18 de marzo de 2016

${ }^{1}$ El mejor estudio sigue siendo el de Hu-DeHart, Yaqui Resistance. Un relato reciente y accesible en ТАIво II, Yaquis. 
y política, esta nueva ofensiva tuvo el efecto de dividirla. Unos decidieron huir de la violencia hacia Arizona, otros encontraron empleo en distintas regiones de la entidad, algunos incluso apoyaron a los mexicanos, y un grupo, bastante numeroso, decidió enfrentar a los invasores y defender su territorio. Tal división no era tajante pues, a pesar de todo, algunos yaquis pacíficos o emigrados colaboraron con los rebeldes e incluso se sumaron ocasionalmente a sus filas. Del lado sonorense mexicano tampoco había una unidad completa en torno a esta guerra, ya que muchos empresarios y hacendados apreciaban su gran valor como fuerza de trabajo. Sin embargo, poco a poco se impuso cierto consenso sobre la imposibilidad de un arreglo pacífico de la cuestión yaqui.

Las líneas generales de esta política, sorprendentemente, no variaron con la llegada de las nuevas élites políticas revolucionarias. Si cabe, el único cambio consistió en ampliar la magnitud de los proyectos de colonización e irrigación, pues en lo que tocaba a la estrategia para lograrlos, se persistió en una solución por la vía de las armas, la deportación y la separación de las familias yaquis. En todo caso, la nueva guerra contra los revolucionarios acentuó la brecha entre las dos partes y dejó claro que sus proyectos históricos eran incompatibles.

Aun cuando toda la información sobre este periodo procede de las fuentes mexicanas, es importante señalar que ahí también se encuentran documentos que permiten asomarnos a la perspectiva que tenían los yaquis de la situación. Después de analizar ambos puntos de vista, creo posible sostener que sus formas de vida y la interpretación que hacían de los acontecimientos no tenían mayores puntos de contacto, de tal suerte que su relación en esos años, 
aun cuando fue muy intensa, nunca fue un diálogo: se trató de dos monólogos tan distantes que no podían conducir a ninguna negociación ni acuerdo pacíficos. ${ }^{2}$ Lo grave fue que tales monólogos estaban sostenidos por la fuerza de las armas y los más fuertes, los revolucionarios, se mostraron incapaces de entender las razones de los yaquis. Hacerlo hubiera significado renunciar a sus proyectos modernizadores y nacionalistas.

\section{EL PORFIRIATO, LA MODERNIZACIÓN Y LA GUERRA DEL YAQUI}

Ante todo hay que empezar por establecer algo que parece trivial. El profundo sentido de continuidad con el pasado, que caracterizaba a la nación yaqui, no tiene que ver con nuestras nociones de historia mexicana. Su cronología era otra, otros sus sucesos fundamentales, otro el sentido de la vida yaqui en ese transcurrir. Ciertamente su identidad se basaba en una fuerte memoria social, pero en ella aparecían mezclados indisolublemente elementos mítico religiosos con hechos y acontecimientos históricos. Entre los primeros están los dos mitos de fundación: uno que ubica el diluvio en territorio yaqui y otro que se conoce como el Canto de la Frontera. Según éste, cuatro profetas yaquis recibieron la visita de una bandada de ángeles que los acompañó mientras caminaban, predicaban y cantaban, a lo largo de la frontera. "Al cantar fueron definiendo la extensión del territorio

${ }^{2}$ Esta interpretación está fundada en los trabajos de Alfred Schutz. Puede verse, en particular, "El forastero. Ensayo de psicología social", en Schutz, Estudios, pp. 95-107. 
tribal yaqui y designando los hitos que marcaban claramente los límites". Por esa razón, "los yaquis se consideraban propietarios al servicio de Dios, de esa vasta extensión de tierra" (véase el mapa 1).

Este mito tenía un complemento laico: el rey de España, probablemente a raíz de la rebelión de 1740, habría sancionado en ese año esos linderos mediante un título de propiedad otorgado a los yaquis. Tal documento, si existió, es probable que se haya perdido o fuera robado, pero lo importante es que en adelante sería un argumento central del discurso yaqui. Por lo demás, es verdad que a fines de 1739 el virrey Juan Antonio de Vizarrón y Eguiarreta (gobernó de 1734 a 1740) recibió a una delegación yaqui encabezada por Juan Ignacio Usacamea, el Muni (al que nombró capitán), y aprobó sus demandas, incluyendo el respeto a sus tierras. ${ }^{4}$

Es necesario tener presente que en esa larga historia las guerras no terminaron con una clara victoria española o mexicana. Todas fueron terribles para los yaquis, pero aun diezmados y dispersos, al final siempre hubo algunos miles que se mantenían en su territorio sagrado. Todavía en 1939, unos pocos seguían "alzados" o rebeldes en sus montañas. ${ }^{5}$

Aparte de las guerras propias, durante el siglo XIX habían participado en las luchas armadas que se libraron en Sonora, al lado de los más disímiles aliados: los realistas,

3 Tales límites, para el observador externo, no eran muy precisos. Spicer calculó que las 400000 ha concedidas por el presidente Cárdenas representaban poco más de un tercio de sus posesiones originales. SPICER, Los yaquis, pp. 213, 215 y 334-335.

${ }^{4}$ Spicer, Los yaquis, p. 46; Hu-DeHart, Adaptación, pp. 54, 62-63.

${ }^{5}$ SPICer, "Eventos", pp. 246-258. 


\section{Mapa 1}

\section{CAMBIOS EN EL TERRITORIO TRIBAL DE LOS YAQUIS HASTA 1939}

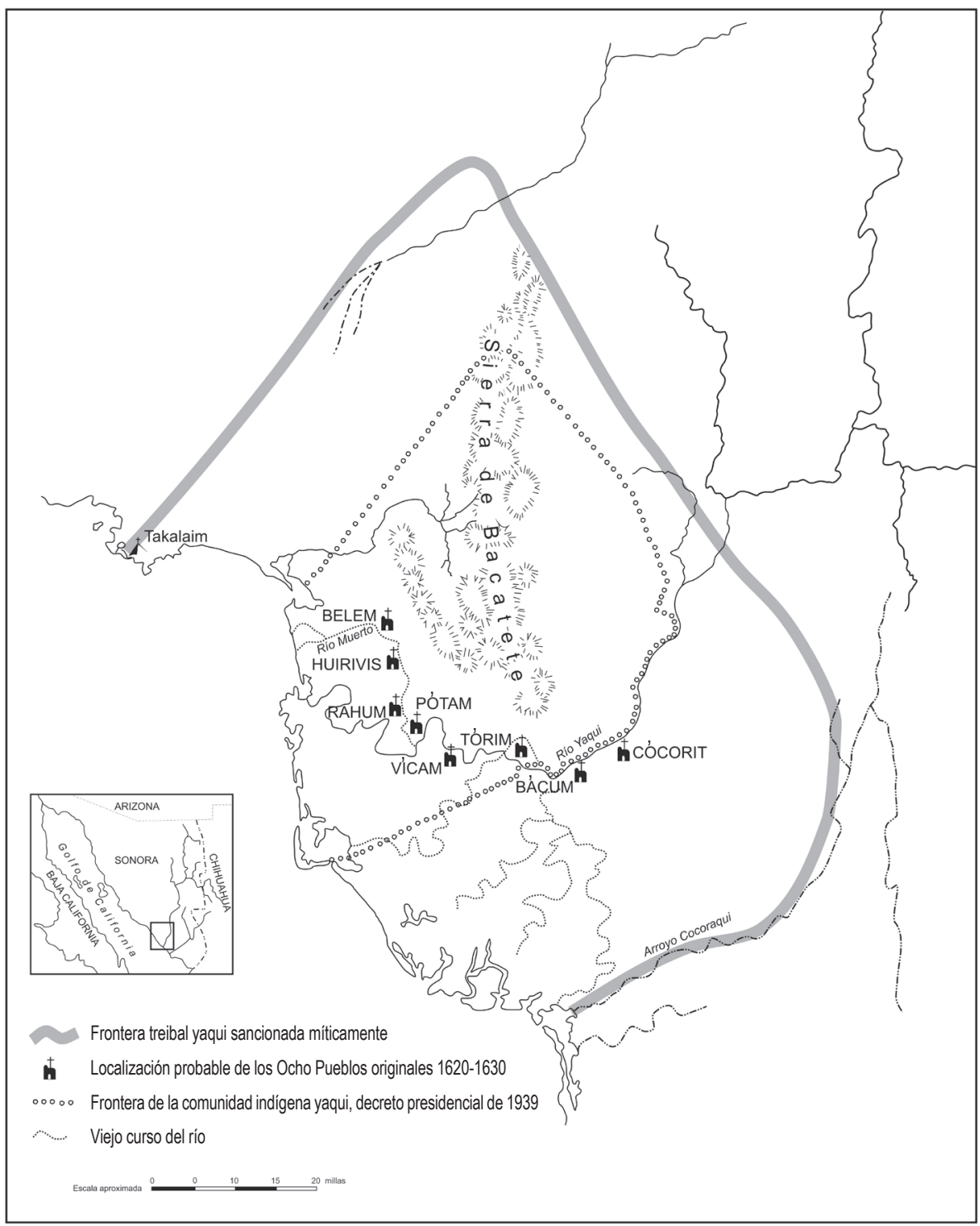

Fuente: Spicer, Los yaquis, p. 335. 
Manuel María Gándara o los imperialistas franceses, pero su compromiso con ellos no era ideológico o nacionalista. Simplemente querían que se respetara su territorio y esas alianzas parecen haber sido meramente coyunturales y pragmáticas. Lo importante es que, a despecho de su propia versión mítica, fue hasta el siglo xIx, en medio y por medio de estas guerras propias y ajenas, cuando parece haberse configurado la identidad nacional yaqui. ${ }^{6}$

La vida yaqui era una vida llena de exigencias, responsabilidades y escrutinio público. Parece haber dejado muy poco margen a la individualidad fuera de esa intensa vida social y comunitaria, lo que seguro generó tensiones y angustias en los individuos que comenzaban a tener información de y roce con el mundo mexicano. Pero entretanto, estaba claro para ellos que "el servicio público era muy arduo” y difícil. El yaqui tradicional vivía, ciertamente, atrapado en el mantenimiento del ciclo vital durante el año ceremonial. Los pesados deberes de esa vida la hacían, como resume Spicer, "una vida muy dura".

Este modo de vida, que alcanzó su esplendor hacia 1880, fue posible porque en el agitado siglo XIX sonorense, los pueblos yaquis, en efecto, lograron vivir con autonomía. Sin embargo, tanto el crecimiento demográfico de Sonora como la estabilidad institucional liberal y el paso del ferrocarril por su territorio, pronto amenazaron su modo de vida y su existencia misma ${ }^{8}$ (véase el mapa 2).

6 Acuña, Caudillo; Hu-DeHart, Yaqui Resistance, pp. 91-93; Spicer, Los yaquis, pp. 276-282, y HERNÁNDEZ, Insurgencia.

7 SPICER, Los yaquis, p. 257.

8 Hu-DeHart, “Development”, p. 76 y ss, y Yaqui Resistance, p. 99 y ss. También OKada, "El impacto”. 


\section{Mapa 2}

\section{LA SIERRA DE BACATETE Y EL RÍO YAQUI, C. 1900}

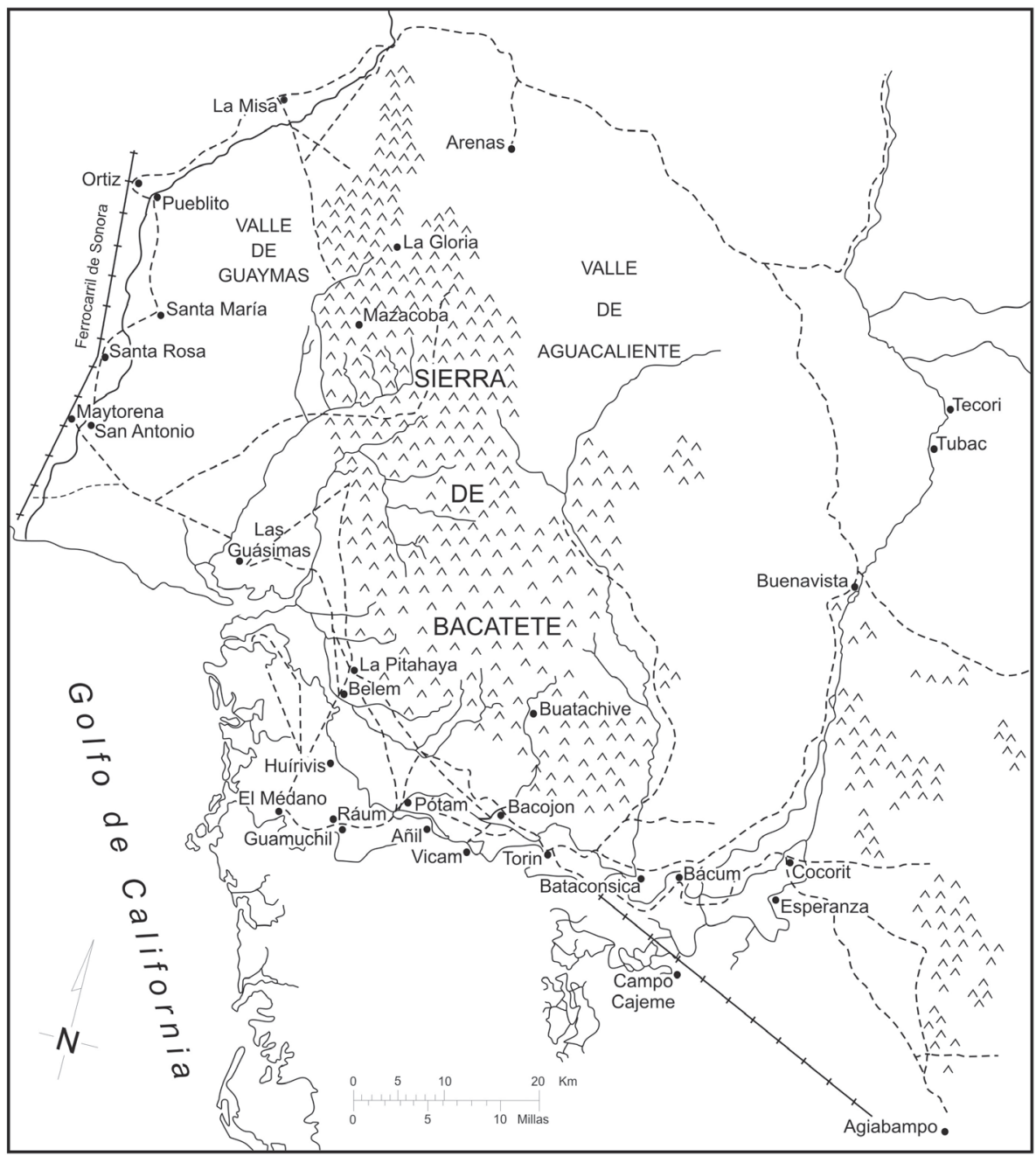

Fuente: Hu-DeHart, Yaqui Resistance, p. 224. 
La población de Sonora en el siglo xix tuvo un comportamiento atípico, pues creció hasta mediados de siglo (271000 habitantes), pero a partir de allí descendió hasta 1870 (108211 pobladores). Luego comenzó un lento crecimiento que se aceleró a partir de 1890, de modo que a fines de siglo por fin se sobrepasaba la cifra de 30 años antes (221682 habitantes). ${ }^{9}$ Frente a esos números, la población yaqui representó durante ese siglo un porcentaje considerable, pues hacia 1840 pudo haber estado compuesta por 50000 individuos, de los cuales unos 22500 residían en los ocho pueblos. Era una nación pequeña, pero la diferencia respecto del total de Sonora no era abismal; se trataba del único pueblo indígena que en el periodo español tuvo un leve crecimiento poblacional y pronto fue dominante en todo el noroeste. En cambio, para 1900 quedaban tal vez menos de 30000 , y de ellos sólo la mitad habitaba de manera dispersa en el Valle del Yaqui. Este descenso demográfico coincidió con el afianzamiento de los gobiernos porfiristas y el crecimiento poblacional mexicano. En parte se debió a las víctimas de guerra, aunque también muchos huyeron de ella hacia Arizona. Sin embargo, como sabemos, todavía faltaba lo peor, la deportación masiva de yaquis a Yucatán entre 1902 y 1908, que las cifras más confiables ubican entre 5000 y 7000 personas. En fin, después de la pesadilla porfirista, hacia 1910 parecen haber quedado sólo unos 15000 yaquis dispersos por Sonora y otras entidades, mientras unos 3000 seguían en sus queridos pueblos. ${ }^{10}$

9 I. Almada, Breve historia, pp. 128-129.

10 FABILA, Las tribus, pp. 127-130; SPICER, Los yaquis, pp. 155, 192 y 198; Padilla, Yucatán, pp. 130-132; Hu-DeHart, "Solución”, pp. 153-154; Hu-DeHart, Yaqui Resistance, pp. 162-163. 
Estas cifras ayudan a entender por qué la presión hacia los ricos recursos de su territorio fue soportable hasta 1880 aproximadamente. Y, por el contrario, también explican que el pueblo yaqui pudiera vivir con cierta holgura en las extensas y fértiles orillas del río Yaqui, de los bosques, el mar y las montañas del Bacatete, y que pudiera hacerlo con su propia religión y sus propios gobiernos. Sin embargo, hacia 1880 , los liberales porfiristas decidieron acabar con esa anomalía de tener - como decía el gobernador Ramón Corral- dentro del estado una "nación separada, independiente por completo, que tiene su régimen de gobierno diverso del nuestro". ${ }^{11}$

Lo hicieron mediante una triple estrategia: la guerra, la colonización y la ocupación militar, que incluyó al final la deportación. La guerra fue terrible: duró de 1882 a 1909 y fue ejecutada ahora por el ejército federal, que ganó las importantes batallas de Buatachive (1886), Mazocoba (1900) y Gavilán (1904). Lo novedoso, en todo caso, fue que Cajeme, quien había llegado al grado de capitán en el ejército federal y había combatido contra los imperialistas, reconvertido en capitán general de los yaquis, modernizó su ejército, estableció una especie de sistema fiscal, formó una caballería y utilizó tácticas y armamento occidentales. Por ejemplo, fortificó un punto llamado Añil (entre Pótam y Bácum) en el que ganaron un combate al ejército en 1885. Sin embargo, los dos principales jefes yaquis en el periodo, que encabezaron la resistencia, terminaron capturados y ejecutados, Cajeme en abril de 1887 y Tetabiate en julio de 1901, de modo que en adelante unos 2500 yaquis se

${ }_{11}$ Corral al Congreso de Sonora, 29 de noviembre de 1880, en Troncoso, Las guerras, p. 125; Hu-DeHART, Yaqui Resistance, p. 94. 
refugiaron en las montañas y siguieron peleando mediante una especie de lucha guerrillera. La diferencia respecto de las guerras anteriores es que ahora el ejército se convirtió en uno de ocupación, lo que permitió el avance de las obras de riego y el asentamiento de colonos blancos y mestizos en el territorio. Al final el jefe Luis Bule firmó en enero de 1909 una nueva paz que dio un pequeño respiro al acosado pueblo yaqui. De cualquier manera, para 1910 "estaba bastante avanzado el proceso de transformación de los pueblos yaquis en pueblos mexicanos"12 (véase el mapa 3 ).

De hecho, el contacto entre yaquis y mexicanos durante el siglo XIX se había intensificado en toda Sonora, lo que explica el elevado porcentaje de yaquis que no residía en los pueblos. Básicamente, estaban empleados como peones agrícolas, como mineros y como servicio doméstico, y pronto tuvieron una bien establecida fama de buenos trabajadores. La política de exterminio y deportación, por ello, encontró cierto rechazo entre hacendados y propietarios de minas, pues la fuerza de trabajo era más bien escasa en Sonora. Pero tal "solución", por otra parte, estaba justificada por el hecho de que estos yaquis "mansos" o integrados muchas veces ayudaban a los que se encontraban alzados con provisiones y recursos, pero también porque podían ir y venir entre tales trabajos y la resistencia en sus montañas.

Los ámbitos y la manera en que se dio esta relación entre ambos mundos en este mismo periodo (fines del XIX), por un lado, dejaban muy poco espacio para la integración y por el otro cancelaron toda posibilidad de llegar a un arreglo

12 Spicer, Los yaquis, p. 286; Hernández, Insurgencia, p. 110 y ss.; Hu-DeHart, Yaqui Resistance, p. 190 y ss; Corral, "José María Leyva Cajeme”, p. 154 y ss. 


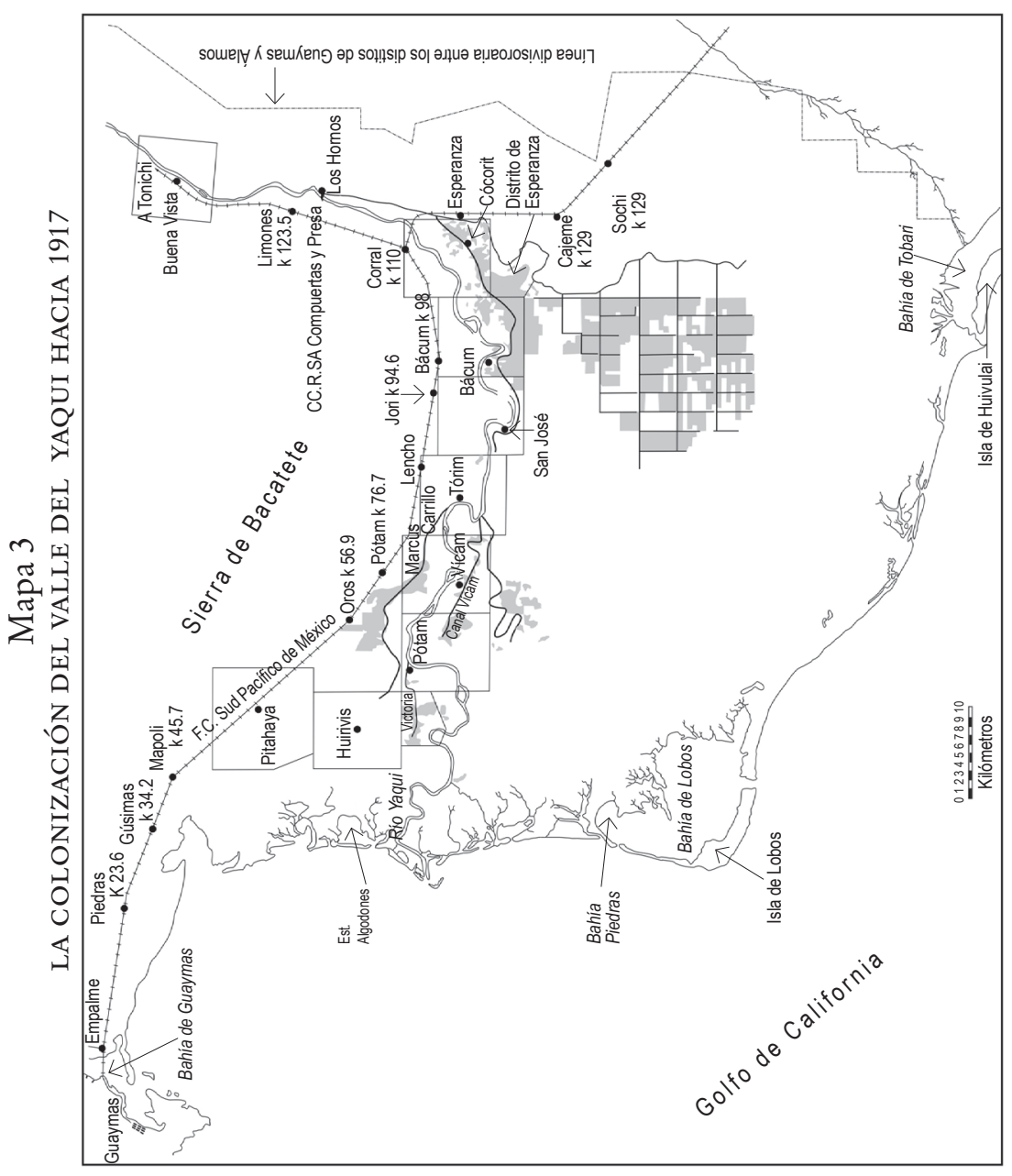

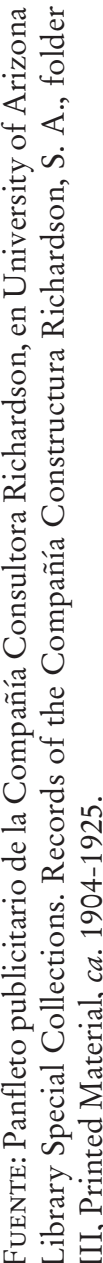


pacífico. En el fondo se trataba de una lucha entre dos tipos de sociedad y dos visiones del mundo con prácticamente ningún punto de contacto. Por ello se entiende que el grueso de ambas partes del conflicto operara con una imagen estereotipada del otro, que aun cuando no fuera compartida por todos los individuos, sí orientaba las actitudes de cada bando. Los yaquis veían a los sonorenses como un pueblo de guerreros innatos, individuos agresivos y furiosos, incapaces de conservar la paz entre ellos y con otros grupos pacíficos; se trataba de gente desordenada que no respetaba fronteras establecidas, pues invadían sin aviso y luego defendían con las armas lo que habían robado. Tampoco respetaban a las autoridades de los pueblos y pensaban que la dirección verdadera del pueblo era la militar. Y, en fin, era un pueblo que simplemente simulaba ser católico, pero que ignoraba cuál era el comportamiento religioso correcto. Por ello, no es sorprendente que en la mitología yaqui los mexicanos hubieran "sido hechos con la basura que Dios había barrido y hecho a un lado, y que el primer mexicano salió de esa pila de basura agitando los brazos, hablando con mucha volubilidad y amenazando a todo el mundo". ${ }^{13}$ Por lo demás, recordemos que tal imagen de los mexicanos se transmitía de forma oral mediante la educación familiar y religiosa. Por ejemplo, en las ceremonias anuales de pascua, muchos seres malignos llevaban máscaras que imitaban a los soldados mexicanos, que al final eran quemadas en una gran hoguera.

Tal imagen es comprensible si pensamos que aparte de los colonos que venían a invadir su tierra, los yaquis trataban ante todo a los soldados, autoridades y al sistema de

${ }^{13}$ Spicer, Los yaquis, p. 197. 
justicia mexicanos. Y en el caso de los que lograban trabajar en minas y haciendas, se les reservaba el trato del último peldaño de la escala social. La deportación y la entrega de niños y niñas a familias de las grandes ciudades en calidad de servicio doméstico, por cierto, no ayudaba a eliminar estas impresiones del mundo "civilizado". Muchos perdieron a parientes que murieron en el largo viaje a Yucatán y Valle Nacional, o bien en las agotadoras faenas en esos lejanos lugares.

Por lo que se refiere a los sonorenses, fue en la época porfirista cuando se configuró una lectura del conflicto desde el mirador del progreso, la civilización y el gobierno constitucional. Para ellos la existencia de la sociedad yaqui - con su independencia, su rechazo de la ciudadanía y la propiedad individual, sus costumbres semisalvajes, su forma de vida atrasada, sus formas de gobierno rudimentarias - era inadmisible. Como escribía el doctor Manuel Balbás, médico militar del ejército que combatió a los yaquis a fines de siglo, aun si el derecho de posesión por varios siglos constituía un título legítimo de propiedad, "esta riquísima zona no es debidamente explotada por los indios y el progreso exige que lo sea”. Este progreso estaba hecho de grandes exigencias "y el pueblo que no se amolda a ellas, tiene que sucumbir”. Por eso la guerra del Yaqui, bien decían, eran una guerra entre dos pueblos, dos naciones, una de las cuales la concebía como una guerra santa civilizadora contra los bárbaros. Como resumía el propio Balbás, las causas de la prolongación indefinida de la campaña, desde el punto de vista de los indios, eran: 
Los derechos de propiedad que alegan sobre las tierras mencionadas.

Su anhelo de permanecer completamente sustraídos al gobierno del yori, para disfrutar una vida semisalvaje, con absoluta libertad e independencia.

La falsa idea que tiene formada de su patria, no considerándola constituida por todo el país llamado México, sino única y exclusivamente por la región limitadísima del Yaqui.

$\mathrm{Y}$ en el fondo de todas las causas, la fundamental y esencial de ellas: la ignorancia de estos indios, naturalmente inteligentes, pero absolutamente privados de instrucción. ${ }^{14}$

Por eso no había en realidad solución pacífica posible a pesar de los intentos de convencerlos para convertirse en propietarios privados. Porque se trataba de un modo de vida al que incluso los que trabajaban fuera regresaban cuando podían. El suyo era una especie de territorio libre que no tenían en ninguna otra parte. Aunque podían aceptar las reglas de los yoris en el exterior, no querían hacerlo ahí. Lo que rechazaban era un tipo de vida que conocían, porque lo habían visto impuesto a los otros grupos indígenas como los mayos. Por eso para ellos se trataba de defender sus campos, sus hogares y su sagrado territorio tribal contra un enemigo que había dado muestras de ser despiadado. Como le escribieron los ocho pueblos al general Luis E. Torres en julio de 1899:

Díganos ahora: lo que queremos es que salgan los blancos y las tropas. Si salen por las buenas, entonces hay paz; si no declararemos la guerra. Porque la paz que firmamos en Ortiz fue con

${ }^{14}$ Balbás y Hernández, Crónicas, p. 94. 
la condición de que se fueran tropas y blancos y eso todavía no lo cumplen: al contrario, en lugar de cumplirlo fueron a quitar las armas. De suerte que ahora son ustedes de todo el negocio, y nosotros no tendremos la culpa de todas las desgracias que haya. ${ }^{15}$

Lo cierto es que hacia 1910, el dominio mexicano había avanzado a tal punto que no era remota la posibilidad de la extinción del pueblo yaqui como entidad autónoma. Ese proceso sólo en parte fue detenido por la revolución mexicana.

MADERO Y LOS YAQUIS: CRÓNICA DE UN DESENCUENTRO

Aguilar Camín escribía a fines de los setenta del siglo pasado que la historia reciente del pueblo yaqui podría escribirse como si no hubiera existido la revolución mexicana. Sin embargo, los miembros de la nueva élite política tuvieron que ocuparse casi constantemente de la cuestión yaqui. El primero de ellos fue Madero, quien en su libro La sucesión presidencial en 1910 y durante su gira proselitista por Sonora había hablado de la situación de los yaquis, a quienes, decía, se había hecho una guerra "interminable”, "inicua", "infructuosa", en vez de reconocérseles "como dueños de la vasta extensión de terreno que ocupaban”. El hecho de que "no reconocían de un modo absoluto la autoridad federal, no era motivo para exterminarlos, pues con paciencia se hubiera logrado introducir entre ellos la luz de la enseñanza, las ventajas de nuestra civilización, y muy pronto, en mucho menos tiempo que el que se ha necesitado para

15 Troncoso, Las guerras, pp. 125-126. 
exterminarlos, se hubiera logrado civilizarlos". ${ }^{16}$ No tenemos constancia de que los jefes yaquis se enteraran directamente de tales discursos, pero es posible que fueran parte de los argumentos con que Fructuoso Méndez y Pedro García convencieran a jefes como Sibalaume y Mori de sumarse al movimiento armado en la región del río. ${ }^{17}$

Consecuente con sus dichos, al triunfo del levantamiento armado, durante los últimos días del mes de agosto de 1911, Madero se reunió en Tacubaya ("en representación del Gobierno federal”) con una comisión de gobernadores y representantes de los más importantes jefes yaquis: José Sibalaume, Ignacio Mori y Juan Espinosa. La conformaban Pedro García (enviado de Espinosa), Benito Matus (enviado de Sibalaume y Mori), Gregorio Matus, Domingo Tesaumes, Juan Luis Mapaumes, Juan Ríos, Juan María Rosas, Francisco Alamera y Juan Sipol. También estuvieron dos representantes del gobierno de Sonora, Dionisio Lacarra y Alberto Morales. En realidad, no parecía una buena decisión haber elegido esas fechas. Madero no tenía en ese momento ningún cargo y estaba muy ocupado tratando de sacar adelante la candidatura de Pino Suárez a la vicepresidencia en la convención del Partido Constitucional Progresista. Además, Maytorena justamente tomaba posesión del gobierno de Sonora el $1^{\circ}$ de septiembre, fecha en la que se firmó el Convenio. De hecho, al día siguiente de la firma, el secretario de Gobernación, Alberto García Granados, declaró que "el Gobierno Federal no ha autorizado al señor

\footnotetext{
16 Aguilar Camín, “Los jefes”, p. 18; Madero, La sucesión, pp. 195-196.

17 BReceda, México revolucionario, p. 22; Rivera, La revolución, pp. 201 y 216; RAMÍREZ, La participación, pp. 36-37.
} 
Madero para tratar con los comisionados yaquis, ni menos para aprobar ningún convenio con ellos". ${ }^{18}$

A pesar de la inconsistencia legal de esta negociación, es importante porque se trató del primer intento revolucionario de establecer una relación distinta con los yaquis. Además, Madero firmaba a sabiendas de que difícilmente perdería las elecciones del 15 de octubre. El documento producido también parece haber sido realmente un "convenio" entre ambas partes. Curiosamente se hicieron cinco ejemplares: dos para los yaquis, uno para el gobierno de Sonora, otro para el gobierno federal y otra para Madero. Los acuerdos tomados fueron:

1. "El Gobierno Federal cede a los indios yaquis los terrenos de propiedad nacional en los ejidos de los pueblos de Tórin, Vícam, Pótam y Raum, así como el Canal de Vícam.” Tales terrenos se abrirían al cultivo "por cuenta del gobierno" con el trabajo de los yaquis, quienes recibirían un salario de un peso diario. Cuando estuvieran listos, se haría un reparto de tierras por los ingenieros "de acuerdo con los gobernadores de los yaquis”, a razón de 3 hectáreas por matrimonio, 2 a solteros mayores de edad, hombre o mujer, y 1 por niño. Se les daría un título de propiedad con la condición de que tales propiedades no podrían ser vendidas, hipotecadas o gravadas por 30 años.

2. El reparto se haría después de la primera cosecha, y a cada familia se le daría un tronco de mulas con sus aperos.

3. El gobierno pondría una proveeduría para distribuir provisiones a los nuevos colonos antes de la primera cosecha.

18 Taracena, La verdadera, pp. 390-392: Cumberland, Madero, pp. 189-191. Taylor, equivocadamente afirma que el gobierno de De la Barra firmó el tratado. TAYLOR, La gran aventura, p. 318. 
4. Se establecerían escuelas "y todos los yaquis se comprometen solemnemente a cumplir con las leyes de instrucción primaria, obligando a todos los niños, en edad de asistir a la escuela, hasta los catorce años, que vayan a ellas".

5. El gobierno construirá una iglesia en cada pueblo.

6. Los colonos yaquis no pagarán contribuciones por 30 años.

7. "Los yaquis nombrarán sus autoridades locales, pero reconocerán la general del Estado y la de la República Mexicana.”

Finalmente, en el acuerdo se establecía que, en caso de diferencias, serían arregladas ante los tribunales y que "en ningún caso se recurrirá a las armas, pues los yaquis protestan sumisión completa al actual gobierno, al que están dispuestos a ayudar como todos los mexicanos, sólo en caso de una guerra extranjera". ${ }^{19}$

Llama la atención que los enviados hayan aceptado la posibilidad de un reparto de su tierra, pero hay que resaltar el hecho de que su nación nunca se había encontrado en una situación de debilidad como la de entonces. Además, la llegada a la gubernatura de Maytorena parece haber dado confianza a algunos jefes de que atendería sus demandas. De hecho, justamente con el triunfo de los maderistas, se dieron dos procesos distintos: por un lado comenzó un lento regreso de los yaquis a su tierra y la repoblación de sus queridos pueblos, y por el otro nuevamente las partidas de yaquis levantiscos tuvieron oportunidad para bajar a los valles y a los caminos. ${ }^{20} \mathrm{Y}$ también hay que considerar que

19 TARAcena, La verdadera, pp. 390-391; "Madero pacta con los yaquis”, en Cuevas, Sonora, pp. 283-284; y Henderson, “Un gobernador”, p. 177 y ss.

${ }^{20}$ Moctezuma, De pascolas, p.171; Holden, Mujeres yaquis, p. 198 y 
los jefes más importantes, Espinosa, Mori, Matus y Sibalaume, el más recalcitrante de ellos, no estuvieron presentes en las negociaciones y que posiblemente los enviados no fueran muy competentes en el idioma y las prácticas políticas de los mexicanos. ${ }^{21}$

En todo caso, faltaba ver qué pasaría al intentar llevar a la práctica estos acuerdos. Madero tomó posesión de la presidencia el 6 de noviembre y poco después decidió enviar al general sudafricano Benjamin J. Viljoen, veterano de la guerra bóer y consejero personal suyo en la revolución pasada, a Sonora, en calidad de Comisionado de Paz del Yaqui. Si tal decisión parecía confirmar la importancia que daba al asunto era, en cambio, bastante extraño que designara para el caso a un extranjero sin conocimiento de Sonora, de los yaquis y de las complicadas relaciones entre los distintos poderes civiles y militares en México. En esa ocasión estuvo poco tiempo en Sonora, pues regresó en diciembre a la Ciudad de México, junto con Maytorena y un grupo de enviados yaquis, para entrevistarse con el presidente acerca de la delicada cuestión de las tierras planteada en el convenio. ${ }^{22}$ Viljoen, después de una breve estancia en El Paso, tal vez para tratar su asma, a mediados de enero de 1912 ya se había instalado en Guaymas. Ahí se enteró de que los yaquis

ss.; Ruiz, Tres procesos, pp. 87-89; Aguilar CAmín, La frontera nómada, pp. 166-167.

21 Breceda, México revolucionario, p. 27.

22 Vale la pena señalar que para ese entonces Viljoen había obtenido la nacionalidad estadounidense, pues había llegado a Estados Unidos como organizador de una colonia bóer. Al fracasar ésta, se había establecido como ganadero en Nuevo México. Taracena, La verdadera, p. 432; Aguilar Camín, La frontera nómada, p. 167; Huerta, Memorias, p. 66, y TAYLOR, La gran aventura, p. 92. 
del Bacatete y Bacatetito (gente de Luis Espinosa) estaban "inconformes con el último tratado efectuado en la Capital" y supo que, a pesar de las protestas de acatamiento del convenio, desde noviembre seguían menudeando los robos de ganado en la región del Yaqui. ${ }^{23}$ Peor aún, a pesar de haberles entregado ropa, dinero y otros artículos, el día 25 habían atacado la estación de Mapoli del ferrocarril y asesinado a cuatro trabajadores. Eso confirmaba, desde su punto de vista, que había al menos una porción de la tribu que no quería la paz. Si no se lograba separar a los elementos buenos de los malos, creía "que la única solución de este problema será reclutando un cuerpo de unos mil hombres bien montados y equipados, y con unas cuantas piezas de artillería de montaña subyugar a los yaquis a la fuerza, empleando los métodos usados por los americanos para subyugar a los indios de aquel país”. ${ }^{24}$

De hecho, pronto estuvo entre varios fuegos y no acertaba hacia dónde dirigir sus acciones. Por un lado, había diferencias entre los grupos de Espinosa, Sibalaume y Mori; por otro, el jefe de la zona militar estaba muy reticente a sus solicitudes de tropas, pues Viljoen carecía de mando militar directo y, en fin, los intereses y puntos de vista del gobernador Maytorena no siempre coincidían con los suyos. Si bien Maytorena había comenzado el diálogo con los jefes yaquis desde junio de 1911, parece haber manejado desde entonces un doble discurso; a los yaquis les prometió apoyo en sus demandas con Madero, pero por otro lado le planteaba

${ }^{23}$ Maytorena a Madero, 23 de noviembre de 1911 y 7 de enero de 1912, ambos en AGES, t. 2783.

${ }^{24}$ Viljoen a Madero, 25 de enero de 1912, en SuÁrez, Francisco I. Madero, pp. 135-136. 
al presidente condicionar el regreso de los yaquis de Yucatán y la necesidad de preparar una campaña armada contra ellos. ${ }^{25}$ Viljoen trató, mientras tanto, de convencer a Espinosa de que "los yaqui bien intencionados deben separarse de los malos", pero con escaso éxito. ${ }^{26} \mathrm{El}$ resultado es que no sólo siguieron los robos, sino también asesinatos y amagos de grupos y poblaciones, a pesar de que se instaló la proveeduría prometida en Cruz de Piedra. Las mismas haciendas de Maytorena, La Misa, Santa María y San Antonio, fueron asaltadas en febrero y marzo. ${ }^{27}$

Tan mal estaban las cosas, que Viljoen, a fines de marzo, anunciaba a Maytorena su decisión de renunciar debido a "su pésimo estado de salud". Aunque se quedó un mes más, durante abril los ataques yaquis incluso alcanzaron al ferrocarril, aprovechando que en ese momento se había destinado la mayor parte de las tropas a combatir la rebelión orozquista. ${ }^{28} \mathrm{~A}$ raíz de ello, el general Velasco decidió dar aviso a los jefes Matus, Mori y Espinosa de que se abstuvieran de merodear por los pueblos, pues había dado orden de batir a los indios "que sean avistados, en virtud de no poder distinguir quiénes son unos y quiénes son otros", es decir,

${ }^{25}$ Además, Maytorena mismo estaba interesado en adquirir tierras en el Valle del Yaqui. Alarcón, José María Maytorena, pp. 143-150 y 154; RAMíREz, La participación, p. 46.

${ }^{26}$ Viljoen a Maytorena, 28 de enero de 1912, AGES, t. 2783.

${ }^{27}$ Maytorena a secretario de Gobernación, 26 de febrero de 1912 y 23 de marzo de 1912; ambos en AGES, t. 2783.

28 Viljoen a Maytorena, 23 de marzo de 1912; Maytorena a general J. R. Velasco, 19 de abril de 1912; Moreno a Maytorena, septiembre de 1912. Todos en AGES, t. 2783. El propio Álvaro Obregón, entonces presidente municipal de Huatabampo, repelió con sus reclutas el ataque al tren del 15 de abril de 1912. Obregón, Ocho mil kilómetros, p. 9 y TAYLOR, La gran aventura, p. 322. 
rebeldes o mansos. ${ }^{29}$ Cuando al fin Viljoen se fue, sugirió que se cancelara todo el asunto de las provisiones. Un consternado Maytorena, por su parte, le preguntaba a Madero "qué decir a la tribu" el 23 de mayo. ${ }^{30}$

Un tiempo se mantuvo el suministro, pero hacia fines de julio se decidió por fin suspender los pagos de un peso diario a cada yaqui por concepto de haberes, a cambio de sus servicios en las guardias nacionales. El 31 de agosto Crescencio Valderrain, Valentín Romero y Apolonio Elguero, yaquis de Cócorit, le escribieron a Maytorena para preguntarle los motivos de esa suspensión. En caso de ser cierta la orden, le decían, "cesan nuestros compromisos con usted" y podemos "irnos tranquilos a trabajar". ${ }^{31}$

Tal vez algunos se fueran a trabajar, pero en el incierto contexto de la rebelión orozquista, cuyos últimos partidarios fueron derrotados hasta octubre en Sonora, los actos de yaquis rebeldes se volvieron más frecuentes y osados. El 8 de septiembre, por ejemplo, una partida de más de 150 atacó Colonia Pesqueira, donde resultaron 9 muertos y 9 heridos, entre civiles y soldados. Por esas fechas otro grupo saqueaba Realito a unos $6 \mathrm{~km}$ de La Dura. ${ }^{32} \mathrm{Al}$ mes siguiente otra partida de unos 150 asaltaba el rancho La Despensa, en el distrito de Álamos, donde asesinaron a cuatro vecinos. ${ }^{33}$

29 General Velasco a Maytorena, 19 de abril de 1912, AGES, t. 2783.

30 Maytorena a Madero, 21 de mayo de 1912, AGES, t. 2783.

31 Yaquis a Maytorena, Cócorit, 31 de agosto de 1912, AGES, t. 2782.

32 Maytorena a secretario de Gobernación, 9 de septiembre de 1912, AGES, t. 2782.

33 Maytorena a secretario de Gobernación, 15 de octubre de 1912; Maytorena a J. R. Velasco, ambos en AGES, t. 2782. F. R. Almada, La revolución, pp. 65-71. 
Finalmente, parece que Madero perdió interés en un arreglo general de la cuestión yaqui a raíz del fracaso de su comisionado en conseguir el acatamiento de los acuerdos de septiembre de 1911. En octubre de 1912, sobre esas "depredaciones", decía a Maytorena: "Espero que ahora que dispone fuerzas suficientes pueda someterlos". ${ }^{34}$ Viljoen, de hecho, fue enviado como cónsul a Breslau, Prusia, tal vez para ayudarle en la recuperación de su salud y como compensación a sus trabajos revolucionarios. Y, como sabemos, Madero estaba tratando de mantenerse en el gobierno y debía atender muchos otros asuntos urgentes. En todo caso, el gobernador Maytorena y el jefe de la zona militar, ya sin la presión del orozquismo, trataron de mantener la rebelión yaqui bajo un cierto control. Sólo las tropas de Luis Espinosa parecen haber alcanzado para ese momento la cifra de 1000 hombres y sus "vandálicas correrías" habían provocado la despoblación de algunos poblados situados al norte y oriente de la sierra del Bacatete. ${ }^{35}$

El resultado de esta primera relación entre los yaquis y los revolucionarios no fue alentador. En su informe de gobierno Maytorena hacía un balance de este periodo en términos bastante pesimistas. Según él, no podía pensarse en llegar a una "solución generosa" con el yaqui, ya que: "El pretexto más frívolo, mejor dicho, su instinto de latrocinio y maldad, indúcele a romper los compromisos con el gobierno" ${ }^{36}$ No sabemos si la postura de Madero había

\footnotetext{
${ }^{34}$ Alarcón, José María Maytorena, p. 151.

35 Aguilar Camín, La frontera nómada, p. 253; Taracena, La verdadera, p. 432.

36 Aguilar Camín, La frontera nómada, pp. 253-254.
} 
cambiado hasta ese punto, pero éste ya no tuvo tiempo para volver a ocuparse del asunto.

\section{LOS CONSTITUCIONALISTAS Y LOS YAQUIS}

La relación entre los yaquis y los revolucionarios constitucionalistas fue más compleja. Por un lado, se ha insistido en su participación dentro del ejército constitucionalista, pero, por otro lado, al acentuarse ese dato, se elude o deja de explicar que, una vez en el poder, los revolucionarios acometieron dos nuevas guerras del yaqui, en 1916-1919 y 1926-1927.

El cuartelazo de Huerta y la subsiguiente rebelión de Carranza y los sonorenses fueron hechos muy significativos para los yaquis. Por un lado, porque las acciones militares se desarrollaron en las proximidades de su territorio, y por el otro, porque fueron requeridos como aliados en distintos momentos por las facciones revolucionarias que disputaban el poder. A partir de entonces se recrudeció una marcada división en el comportamiento de los miembros de la nación yaqui.

En primer lugar estaban los yaquis "mansos", es decir, aquellos que "estaban trabajando a gusto" entre los mexicanos. Muchos de ellos vivían en Guaymas, San José de Guaymas y Huíviris, y se quejaban de que, en realidad, tenían enemigos en los dos lados, "porque somos mansos y nosotros pagamos por aquellos bandidos ladrones" que a pesar de los acuerdos y los recursos que el gobierno les daba "siempre siguen matando". En fin, no los dejaban "vivir a gusto" a ellos que "nada más con el trabajo mantenemos a nuestras familias”. Por eso, en mayo de 1912 decían en una 
carta al gobernador Maytorena: “¡Ojalá que se acabaran los alzados! Si aquellos son matadores nos iremos al servicio del gobierno que no que nos maten ellos". ${ }^{37}$

En segundo lugar, había un grupo que ya desde el porfiriato no sólo se había rendido al gobierno, sino que había dado muestras de buscar su integración a la sociedad mexicano sonorense. Entre sus líderes estaban Luis Bule, Lino Morales, Francisco Urbalejo y José Amarillas, quienes se habían rendido en 1908, habían estado en las fuerzas auxiliares de Sonora a fines del antiguo régimen y posteriormente se incorporaron al ejército de Obregón. El primero murió en la Batalla de Santa Rosa (mayo de 1913), pero los otros hicieron una carrera exitosa en el constitucionalismo y en el nuevo ejército federal, e incluso volvieron a combatir contra los propios yaquis alzados. Entre los hombres que les siguieron, curiosamente, se encontraba José María Leyva Cajeme, sobrino de Cajeme. ${ }^{38}$

Sin embargo, lo más notable es que gran número de los yaquis regresó a su territorio y pronto se unieron a quienes se habían quedado en los pueblos y a quienes bajaban de la sierra del Bacatete, en la rehabilitación de sus poblados y de su modo de vida. Al mismo tiempo los más recalcitrantes aprovecharon el aflojamiento de los controles, los cambios de poder y las disputas entre revolucionarios para comenzar una especie de expropiación moralmente fundada

${ }^{37}$ Las citas en Aguilar Camín, La frontera nómada, p. 220; Holden, Mujeres yaquis, p. 237 y ss.

38 AHDN, exp. 2-489. Aguilar Camín, La frontera nómada, p. 239; Bojórquez, Forjadores, pp. 125-135; Holden, Mujeres yaquis p. 237244; Cuevas, Sonora, p. 370; Dabdoub, Historia, p. 200; Zavala, El indio Tetabiate, p. 238. 
de cosechas, animales y bienes de los blancos que estaban asentados en su territorio. Un enviado de Maytorena ubicaba desde abril de 1912 a tales descontentos como gente de Sibalaume, Mori y Matus, es decir, los jefes que habían firmado el convenio con Madero, pero sobre todo señalaba a los fieles a Luis Espinosa, que de hecho se había sostenido por años en el Bacatete y Tocorobampo, y ahora comenzaba a aumentar su fuerza. Todos ellos rechazaron las invitaciones de Maytorena para bajar y hablar con él sobre la paz. Mori, por ejemplo, contestó: "Que se retiren los blancos y ahorita mismo bajo". ${ }^{39}$

Como hemos explicado, a fines de 1912 y principios de 1913, se había dado un fortalecimiento de los rebeldes yaquis, de modo que en el momento del golpe huertista, parecían aliados apetecibles para los revolucionarios de Sonora. De hecho, Aguilar Camín ha argumentado que su odio al ejército federal los llevó a una suerte de alianza "inorgánica y endeble" con los constitucionalistas para combatir juntos al ejército federal. Por eso, Obregón pudo contar con cierto apoyo de los hombres de Mori, Espinosa y Sibalaume en la Batalla de Santa Rosa en mayo de 1913. Sin embargo, estos jefes no estaban dispuestos a seguirlo fuera de su territorio, así que se quedaron ahí, armados, esperando que las promesas hechas para tal alianza, por intermedio de Fructuoso Méndez, se cumplieran. ${ }^{40}$

\footnotetext{
39 Aguilar Camín, La frontera nómada, pp. 216-217. Sobre la división entre los yaquis véanse BRECEDA, México revolucionario, p. 148 y ss; y RAMírez, La participación, passim.

40 Aguilar Camín, La frontera, p. 336; Obregón, Ocho mil kilómetros, pp. 66 y 71 .
} 
Pero no se cumplieron, y peor aún, las grandes propiedades intervenidas en el valle fueron controladas directamente por los revolucionarios para financiar la guerra. Ello llevó a Alvarado a endurecer el trato hacia los yaquis, de modo que éstos siguieron en su actitud levantisca. Espinosa, Matus, Mori y otro jefe llamado José Méndez, explicaban sus motivos en un manifiesto de agosto de 1913, firmado en Cócorit.

1. Después de haber sido expulsados de nuestros pueblos, la necesidad nos obliga a comer de lo que hallemos o podamos hallar: así es que todo reclamo por animales y cereales que en nuestros pueblos habitados por el hombre recojan para nuestro uso y alimento común será hecho nulo a los que estén posesionados de nuestras tierras y se dicen dueños de Haciendas.

2. Tomando en consideración que hay muchos habitantes que desean salir de esta región por temor de nosotros; pueden hacerlo y para ello ya hemos tratado con el representante del Gobierno del Estado encargado de tratar con nosotros, que se les proporcione todos los medios posibles a dichas familias, para que tomen el camino que a bien tengan. Nosotros no somos hostiles a nadie sin que para ello haya razón, así es que el temor u odio arraigado que para nosotros tengan está muy mal fundado.

3. Nuestra lucha se reduce únicamente a reconquistar nuestros derechos y nuestras tierras arrebatadas por la fuerza bruta y para ello cooperamos con los demás hermanos de la República que están haciendo el mismo esfuerzo de recuperar dichos derechos y castigar a los caciques del pueblo humilde y productor. $^{41}$

41 “A los habitantes del Río Yaqui”, Cócorit, 20 de agosto de 1913, en AGES, t. 3389, 2a . parte. 
Sintomáticamente, al final ponían un lema que resumía todos sus agravios: "Libertad y tierras". ${ }^{42}$

Las tropas constitucionalistas acantonadas en los pueblos (comandadas por Benjamín Hill y Salvador Alvarado) no permitieron la difusión del manifiesto, y a fines de ese mes se produjo un tiroteo entre ambos bandos en las afueras de Tórim. Por fortuna estaban cerca Fructuoso Méndez y Obregón, quienes rápidamente se trasladaron al lugar del conflicto y negociaron una nueva paz. Lo que dieron para lograrla fue una nueva promesa, la de devolver las tierras "que indebidamente les fueron usurpadas" una vez que el gobierno general se estabilizara. A cambio, los yaquis respetarían vidas e intereses, y notificarían al cuartel más cercano cuando quisieran entrar a algún pueblo. También se comprometían a enviar una copia de los acuerdos a Sibalaume (en la sierra) pidiéndole que los acatara. Un optimista Obregón telegrafiaba a Maytorena el 2 de septiembre de 1913 que con ello el problema estaba "completamente resuelto". ${ }^{43}$

Se equivocaba. El ánimo levantisco de hecho se acentuó al calor de la escisión entre los propios revolucionarios. Entre 1914 y 1916 diversos grupos de yaquis aprovecharon la disminución de la presencia del ejército en su territorio para hostilizar pueblos, haciendas, ranchos y estaciones de ferrocarril. En junio de 1914 un grupo de alrededor de 400 atacó Campo Verde en las cercanías del mineral San Javier, con un saldo de 18 muertos en la parte mexicana. Y en diciembre

\footnotetext{
${ }^{42}$ Hay quien ha querido ver en esto una inclinación zapatista, pero el uso en plural de tierras se refiere, de un modo muy distinto al de los campesinos del centro, a su territorio sagrado.

43 Aguilar Camín, La frontera nómada, pp. 377-378; Ramírez, La participación, p. 54.
} 
otra partida llegó a Estación Serdán, llevándose la ropa del comisario. En 1915 estas acciones se intensificaron. En enero asaltaron el rancho El Limón, en marzo asesinaron al presidente municipal de Suaqui Grande, y en el verano llegaron a atacar a las poblaciones del Valle del Yaqui y San José de Guaymas. En Pótam su ataque fue rechazado luego de una batalla de tres días, pero para diciembre los pobladores de Bácum informaban que no podían sembrar, pues unos 700 yaquis los tenían en un "estado de sitio". ${ }^{44}$ La situación se tornó tan grave para los colonos agrícolas extranjeros, que después de las primeras incursiones yaquis y su saldo de muertos y heridos, la mayoría decidió abandonar la región por el rumbo de Guaymas. Todavía en julio de 1916 una nueva partida volvió a devastar las propiedades de ciudadanos estadounidenses en la estación Esperanza. ${ }^{45}$

Además, una parte de los yaquis enrolados en el constitucionalismo, encabezados por Urbalejo, José María Acosta, Fructuoso Méndez, Agustín Chávez y Luis Buitimea, decidieron seguir al lado de Maytorena cuando éste y Villa rompieron con Carranza en 1915. Y cuando Villa decidió

${ }^{44}$ John Symonds, superintendente del FFCC Mexicano de Union Pacific a Calles, Estación Torres, 18 de mayo de 1916, AGES, t. 3063; Agricultores de Bácum a Prefecto de Distrito, 21 de junio de 1914, t. 3019; Tesorero General a secretario de Estado, Hermosillo, 8 de febrero de 1915, Filomeno Vázquez a secretario de Estado, Suaqui Grande, 2 de marzo de 1915; Vecinos de Suaqui Grande a Gobernador, 14 de marzo de 1915; Prefecto de Distrito a Gobernador, Ures, 3 y 29 de abril de 1915; Presidente Municipal y vecinos de Pótam a Gobernador, 15 de abril de 1915; Secretario de Estado a Calles, 13 de diciembre de 1915; todos en AGES, t. 3019; y Presidente Municipal de Pótam a Gobernador, 8 de febrero de 1918, en AGES, t. 3327.

45 The New York Times, notas de los días (16 mayo, 18 jun. y 28 jul. 1915; 10 jul. 1916). Véase Ramírez, La participación, pp. 73-75. 
retirarse a Sonora para intentar desde ahí rehacer sus fuerzas, se le sumaron temporalmente, sólo para padecer la incompetencia del caudillo en una serie de batallas perdidas en las proximidades de Hermosillo (noviembre de 1915). Al final, hartos y desesperados porque no llegaban ni municiones ni alimentos para las tropas, simplemente decidieron rendirse a los constitucionalistas. Diéguez quería fusilar a todos los jefes y oficiales rendidos, pero tanto Carranza como Obregón intervinieron para salvar sus vidas y amnistiarlos. Obregón, en particular, decidió formar con estos yaquis una fuerza auxiliar que despachó a Pótam. ${ }^{46}$

LOS REVOLUCIONARIOS EN EL PODER Y LA NUEVA GUERRA

La intensa actividad de los yaquis rebeldes en estos agitados años explica que, después de las victorias de Hermosillo, mientras los restos del ejército villista trataban de llegar a Chihuahua, Obregón volviera a ocuparse del problema yaqui. Lo notable es que, en principio, se planteó de nuevo la posibilidad de un acuerdo de paz, de modo que el general Manuel M. Diéguez inició las negociaciones con ellos. Por su conducto, los gobernadores yaquis le hicieron llegar de nuevo sus viejas demandas, las que le parecieron simplemente "inadmisibles", ya que:

[...] entrañaban la exigencia de un absoluto dominio por parte de ellos, en la región que comprende los pueblos de que fueron despojados, con la intransigente condición de eliminar, en

46 Aguilar Camín, La frontera nómada, p. 419, Dabdoub, Historia, p. 195 y ss; Zavala, El indio Tetabiate, pp. 241-242; Katz, Pancho Villa, p. 115. 
sus dominios, a todo elemento extraño a su raza y a sus atavismos. Acceder a ello hubiera significado una retrógrada complacencia [...] si, equivocadamente, a título de una justa reparación debida a las tribus del Yaqui, se sancionaba, en aquella forma, la perpetuación de la barbarie entre ellas y se le extendía dominio aún donde la civilización lo había ya implantado. ${ }^{47}$

Está claro que para Obregón las cosas habían cambiado mucho en dos años. Ahora disponía de un ejército con gran experiencia, acostumbrado a la victoria y bien pertrechado. Pero los yaquis también habían aprovechado esos años de debilitamiento del poder estatal y parecían sentirse listos para una verdadera guerra. En esos días de diciembre de 1915, Obregón, quien estaba en Guaymas esperando a los negociadores, en lugar de una respuesta positiva, supo que una partida de yaquis había atacado a la guarnición acampada al sur de Guaymas, sobre las vías del ferrocarril. Por ello decidió

[...] abandonar en lo absoluto toda actitud conciliatoria hacia los rebeldes, en vista de que éstos demostraron estar poco dispuestos a entrar en convenios razonables, y sólo aprovecharon las concesiones que les habíamos hecho, permitiéndoles acampar en Tórim y otros puntos del sur del Estado, comprendidos en el Valle del Yaqui, para cometer fácilmente sus acostumbradas depredaciones, quizás juzgando debilidad por parte nuestra, lo que solamente era un sincero deseo de reparar las injusticias y expoliaciones de que habían sido víctimas en épocas pasadas, por parte de los gobiernos dictatoriales.

47 Obregón, Ocho mil kilómetros, p. 471. 
Así, el 21 de diciembre de 1915 dio instrucciones a Manuel M. Diéguez para lanzar una "ofensiva contra esa tribu rebelde", con la que se les hiciera "sentir la fuerza de nuestro Gobierno". 48

En primer lugar, esa fuerza se hizo sentir a la delegación de 38 negociadores yaquis que llegó a Guaymas días después de que Obregón diera esta orden. Lo más probable es que los yaquis hubieran tomado ese tiempo para poner de acuerdo a los ocho pueblos y nombrar los delegados sin saber que ya era inútil. Ahí los apresaron y los enviaron a trabajos forzados a las Islas Marías, sin atender a su carácter de embajadores. El único que pudo salvarse fue a informar lo sucedido, lo que una vez más, seguro, debe haber sido interpretado como una traición mexicana. Los otros, finalmente fueron enrolados en el ejército. Al final sólo sobrevivieron siete de ellos. ${ }^{49}$

Esta fue una campaña en toda regla. Primero estuvo al frente Diéguez, pero pronto lo sustituyó Francisco Serrano, quien tuvo a su mando a más de 11000 efectivos. La primera columna, comandada por Enrique Estrada, instaló su cuartel en Torocobampo y estaba integrada por 52 jefes, 450 oficiales y 5022 soldados. La segunda se asentó en Tetacombiate, fue dirigida por Eugenio Martínez y contaba con 32 jefes, 248 oficiales y 3158 de tropa. Y la tercera por Francisco Manzo, quien tenía a su mando a 37 oficiales, 349 oficiales y 3745 de tropa, y se ubicó en La Misa. ${ }^{50}$ En resumen, una fuerza formidable, con infantería, caballería y artillería

48 Obregón, Ocho mil kilómetros, p. 473.

49 Holden, Mujeres yaquis, pp. 152-154.

50 Francisco Serrano, Informe de Operaciones, 9 de marzo de 1916, FAPECyFT, fondo 3, serie 202, exp. 133. 
de montaña, dirigida por algunos de los mejores y más avezados generales revolucionarios.

Esta nueva guerra duró casi cuatro años y pasó por varias fases. En la primera, de enero a junio de 1916, hubo una ofensiva del ejército mexicano, que consistió en atacar y tomar los campamentos de los yaquis en la sierra, controlar los aguajes disponibles (que en esa anfractuosa y desértica región resultaban estratégicos), y ocupar y controlar los pueblos del río (Tórim, Bácum, Cócorit y Buenavista), así como las estaciones del ferrocarril y los campos agrícolas. La comunicación entre los cuarteles resultaba prioritaria en esa estrategia (por la extensión del terreno y la movilidad del enemigo), de modo que se construyeron caminos y se tendieron redes telegráficas entre ellos.

Aunque los yaquis habían concentrado sus fuerzas en ciertos puntos esperando poder presentar combates formales, fueron derrotados en Aguacalientes, el Bacatete, Las Burras, y sus campamentos fueron ocupados. Poco a poco fueron empujados a posiciones en el sur de la sierra del Bacatete, para sitiarlos ahí y lanzar los ataques finales. Sin embargo, una vez más, un acontecimiento del exterior vino a ayudarles. Con el ataque villista a Columbus (9 de marzo de 1916) y la amenaza de una guerra contra Estados Unidos, el grueso de las tropas tuvo que replegarse a los campamentos cercanos al ferrocarril, para estar disponible y poderse movilizar rápidamente. Eso dio un respiro a un ejército yaqui que conocía perfectamente el terreno en que peleaba y combatía "sólo el tiempo que les convenía para poner a salvo a sus familias y elementos y huyendo o dispersándose después como medida táctica”. De hecho, en ese impasse logró poner a salvo parte de sus familias y 
recursos (sobre todo porque se abrió la ruta hacia el norte, por la Sierra Madre), regresando a una vieja táctica de resistencia, es decir, "fraccionando parte de la tribu para distraer la buena marcha de las operaciones, hostilizando por diversos puntos y conservando sólo en las inexpugnables posiciones en el centro de la sierra, el efectivo que según ellos bastaba para conservarlos como base de sus operaciones". ${ }^{51}$

Ese hábil fraccionamiento, por lo demás, no implicaba mayor problema para un pueblo ejército que en realidad vivía disperso, autónomo y sin mando centralizado desde hacía mucho tiempo. Era una especie de continuación de su forma de vida normal..$^{52}$

Aunque los jefes federales informaban de victoria tras victoria, los meses pasaban sin que este enemigo se rindiera. Era como una especie de pueblo guerrero en movimiento, que iba siendo diezmado lentamente. Por ejemplo, en mayo fueron apresados por el ejército revolucionario 155 mujeres y 111 niños.

A mediados de ese mes de mayo de 1916, el general Enrique Estrada informaba que el enemigo presentaba ya sólo una "débil resistencia" y un estado de desorganización que contrastaban con "la tenacidad y corrección de sus primeros combates”. En las subsiguientes labores de persecución y vigilancia del ferrocarril y los pueblos, se encontraba grupos aislados que no oponían mucha resistencia, pero que casi siempre lograban escapar. Era difícil atrapar a los guerreros, pero cuando se logró, "fueron pasados por las armas".

${ }^{51}$ Enrique Estrada a Plutarco Elías Calles, Informe de Operaciones de la Campaña del Yaqui, Empalme, 30 de junio de 1916, en AHDN, exp. 111, 1-75.

${ }^{52}$ Hu-DeHart, Yaqui Resistance, p. 153. 
Aparte de la persecución, las labores del ejército se orientaron a tres tareas que Estrada juzgaba claves para la completa pacificación de la zona: la reparación del ramal del ferrocarril del yaqui, la creación de colonias agrícolas con yaquis fieles, la repoblación de los pueblos abandonados y, sobre todo, un plan de ocupación permanente de la sierra, que acabara con el "sistema de pillaje organizado", que era "la principal característica de esta última rebelión de los yaquis”.

El detallado informe y plan de ocupación de Estrada terminaba con una interesante sección que titulaba "Justificación de la actual campaña contra los Yaquis rebeldes desde el punto de vista revolucionario y moral". Vale mucho la pena detenerse en ella porque expresa claramente el dilema que esta guerra representaba para los revolucionarios triunfantes.

Estrada comenzaba por señalar que la revolución constitucionalista había acogido "las justas demandas a favor de los derechos de la tribu, canallescamente ultrajados en favor de los intereses del caciquismo". Por ello, la mayor parte de la tribu estaba con el gobierno, "ya pacíficamente en el trabajo, o ayudando a la consolidación del mismo en nuestras filas".

Sin embargo, el ultraje a la justicia más elemental, hecho en la tribu Yaqui por el porfirismo, unido a la torpeza de la campaña federal, cuyas características fueron, la falta de energía en la acción militar y crueldad repugnante con los prisioneros e indefensos, tenía que tener forzosamente una manifestación morbosa en aquella justa rebeldía de la tribu, que se tradujo en la formación de un cuerpo irredento, cuya finalidad era exclusivamente la venganza con sus características de robo y 
asesinato, en correspondencia en los actos de igual género que aquel funesto gobierno sancionó con los suyos.

Este grupo, sin bandera social ni política, fue el que encabezó la última rebelión que el Gobierno Constitucionalista vióse obligado a reprimir, teniendo en cuenta la obligación de garantizar a la sociedad haciendo uso del derecho que tiene de controlar el territorio del cual es responsable. Prueban aquel aserto los miles de trabajadores pacíficos asesinados por los alzados y los centenares de lugares ultrajados por los mismos.

En resumen, la justificación que el Gobierno tiene de destruir un caso morboso de criminalidad endémica, de un grupo inadaptable a la civilización; aun cuando éste sea una de tantas funestas herencias que nos dejó el caciquismo como consecuencia de sus actos criminales. ${ }^{53}$

Aunque Estrada consideraba que la campaña formal había concluido, también reconocía que seguramente los yaquis alzados restantes seguirían "en su labor de asesinato y violación”.

No se equivocaba. La guerra tuvo otra faceta en los pueblos del valle y otros ubicados hacia el norte, pues mientras se libraban las batallas en la sierra y los federales perseguían a las escurridizas partidas de yaquis, otros grupos se presentaban inesperadamente en las poblaciones, en esa labor que para ellos era una expropiación justificada moralmente. Tenían que comer, como decían en el manifiesto de 1913, lo que pudieran hallar.

Para combatir esta otra guerra: móvil, escurridiza, de golpes rápidos y breves, el comandante militar del estado y

53 Estrada a Calles, Informe de Operaciones de la Campaña del Yaqui, Empalme, 30 de junio de 1916, en AHDN, exp. 111, 1-75, p. 11. 
luego gobernador constitucional Plutarco Elías Calles aplicó una estrategia, entre 1916 y 1919, que recordaba mucho algunas de las medidas del "funesto gobierno" al que se refería Estrada. Intentaba cortar todo contacto entre los yaquis rebeldes y los "mansos" (pues se presumía que ahí estaba una de sus fuentes de abasto y provisión), así como restringir el tránsito de los yaquis por los caminos del estado, dada la emigración de los rebeldes hacia el norte. Por lo demás, decretó que los yaquis no podrían circular armados y que incluso los "pacíficos" deberían entregar sus armas. Quien no lo hiciere sería juzgado como rebelde. También determinaba que "después de ponerse el sol ningún yaqui podrá salir de su ranchería", salvo para hacer tareas de riego, siempre con consentimiento y permiso escrito. Los pacíficos, además, estaban obligados a informar de la llegada de cualquier yaqui desconocido a sus respectivas rancherías. Y, por último:

Todo yaqui que sea encontrado sin haber llenado y cubierto debidamente los requisitos que anteceden, serán juzgados como rebeldes y para ello se solicita la eficaz ayuda y cooperación de todos los sonorenses, previniendo que también se impondrán duros castigos a todos los hacendados, rancheros, etc., que no exijan dentro de su esfera de acción y jurisdicción el exacto cumplimiento de estas disposiciones. ${ }^{54}$

Más aún, todas las autoridades, propietarios, patronos o jefes que por "negligencia, descuido o mala fe" no cumplieran con las disposiciones de la circular, "serán considerados

${ }^{54}$ Calles a Carranza, Hermosillo, $1^{\circ}$ de febrero de 1916, en AGES, t. 3063; y Bando de la Comandancia Militar del Estado de Sonora, Hermosillo, 10 de junio de 1916, en AGES, t. 3389, $2^{\text {a }}$ parte. 
como encubridores y cómplices de rebelión y se les juzgará de acuerdo con la ley respectiva". Sólo se exceptuaba de estas medidas a los yaquis al servicio del ejército, pues ya estaban registrados y sólo se movían con permisos escritos. ${ }^{55}$

Pronto hubo resultados de esta medida, apoyada por el gobernador De la Huerta. Las cárceles de Hermosillo y Guaymas se llenaron de prisioneros yaquis desde agosto de 1916, a pesar de que muchos fueron deportados a las Islas Marías (Carranza se negó a deportarlos al interior del país). Muchos de ellos eran, ciertamente, los presos de la guerra (que recordemos eran sobre todo mujeres y niños), pero también es cierto que hubo quienes fueron arrestados a pesar de su notoria calidad de pacíficos. ${ }^{56}$

A pesar de su severidad, estas medidas no detuvieron las acciones yaquis. Por lo demás, pronto fue evidente que otra vía, más difícil de cerrar, de aprovisionamiento de recursos, era la de los exiliados en Arizona, que no sólo daban armas, sino incluso combatientes de reserva. ${ }^{57}$

También es cierto que, desde mediados de 1916, mientras Calles dedicaba sus esfuerzos a la campaña contra los

${ }_{55}$ Aviso del General Jefe de las Operaciones, Empalme, 30 de agosto de 1916, en AGES, t. 3389, $2^{\text {a }}$ parte.

${ }^{56}$ Partes del Alcalde de la penitenciaría de Hermosillo, agosto y septiembre de 1916, en AGES, t. 3045; J. C. Vega a Gobernador, 15 de marzo de 1919; Hill a Calles, 10 de abril de 1919, ambos en AGES, t. 3253; Vecinos de Rayón a Gobernador, 3 de mayo de 1919, en AGES, t. 3227; y Alcalde A. Medina, Lista de reclusos, diciembre de 1919, en AGES, t. 3222. Dabdoub, Historia, p. 206; Zavala, El indio Tetabiate, p. 249, y Macías, Vida y temperamento, p. 226.

57 W. C. Laughlin a Obregón, 18 de octubre de 1919, y Obregón a Calles, 20 de octubre de 1919, en FAPECyFT, Obregón, serie 30100, exp. L-07394, Presidente Municipal de Nogales a Gobernador, 27 de enero de 1920, en AGES, 3389, $1^{\text {a }}$ parte. 
yaquis (fue nombrado jefe de Operaciones a fines de marzo), Adolfo de la Huerta intentó nuevas negociaciones de paz. Los pueblos yaquis otra vez aceptaron las pláticas, tal vez porque tenían un vínculo sanguíneo con el gobernador (su abuela paterna era yaqui), porque habían conocido a su padre y porque había tenido contacto con ellos en los primeros tiempos de la Revolución. ${ }^{58}$ De la Huerta parece haber hecho nuevas promesas, pero la postura de los pueblos siguió invariable, como explicaba Luis Espinosa en el manifiesto del 13 de enero de 1917, dirigido "al pueblo mexicano".

Espinosa empezaba por recordar que habían sostenido durante 37 años "los numerosos empujes de los invasores que por la fuerza bruta han ocupado los terrenos de esta Tribu, y haciéndose llamar civilizadores nos han tenido en la orfandad y la ruina”. Por ello, a las invitaciones del primer jefe del Ejército Constitucionalista respondían que estaban

[...] conformes con sus fraternales frases y prodigios, pero deseamos que se retiren todos los destacamentos en el Río Yaqui que estén tendidos en los linderos de la tribu. Yo, como hombre de bien y honrado para cumplir mis palabras, di órdenes a los generales Matus y Mori para que se bajaran a los pueblos de Vícam y Pótam y yo estaré en mi lugar esperando que se me desocupen los demás pueblos para colocar poco a poco el resto de los habitantes de la Tribu, y $[\ldots]$ con este hecho habremos dado pruebas de que queremos paz y felicidad para nuestra raza y para la de ustedes porque la experiencia nos hace

${ }^{58}$ Huerta, Memorias, pp. 13-15; Dabdoub, Historia, p. 211. 
ver que nunca podremos estar en paz viviendo entre las bayonetas ni con las bayonetas en la mano. ${ }^{59}$

La espera de nuevo fue infructuosa. De la Huerta, a pesar de sus buenas intenciones, no podía realizar el prodigio de desocupar los pueblos. De hecho, aunque parece que hubo un pequeño periodo de paz posterior a esas conversaciones, fue uno breve y frágil, pues nunca dejó de haber incursiones yaquis durante 1916. Sin embargo, un grave incidente abrió de nuevo las hostilidades en mayo de 1917. Un grupo de yaquis que a raíz de esas negociaciones había bajado a la estación de Lencho (a $8 \mathrm{~km}$ al sur de Pótam) para hacer una pascola, fue atacado alevosamente por fuerzas del general Fausto Topete. Como explicaron más tarde: “estando nosotros dormidos asaltó nuestro campamento matando niños, mujeres y ancianos, traición que ni en los tiempos de Porfirio Díaz habíamos experimentado semejante crueldad [...]. Ahora estamos convencidos que el Gobierno no tiene palabra" ${ }^{60}$ Era natural que los restos de la escasa confianza yaqui en el gobierno se evaporaran.

En cuanto tomó posesión nuevamente de la gubernatura (30 de junio de 1917), Calles pidió licencia para seguir al frente de la campaña (15 de julio) y se dedicó en el segundo semestre de ese año a preparar y lanzar una nueva ofensiva.

59 Dabdoub, Historia, p. 203; Huerta, Memorias, pp. 100-103.

60 FigueroA, “La revolución”, p. 374. Vale la pena señalar que DABdoub, Historia, p. 204, y quienes han seguido su versión, ubican equivocadamente este incidente en noviembre, pero ello no explicaría las reacciones que siguieron. Fausto Topete, "Campañas y acciones de guerra”, AHDN, exp. 2-721. Spicer, Los yaquis, p. 71 y Olavarría, Cruces, p. 119, para el ciclo de fiestas y la pascola. 
En octubre anunciaba en un manifiesto que se trataba de "una campaña enérgica, definitiva, y si es preciso, terrible, contra la tribu Yaqui, y asegurar la paz en el Estado, sin omitir sacrificio alguno, llegando al exterminio si fuere necesario". ${ }^{61}$ Desde entonces hasta fines de 1919 la guerra siguió un curso muy parecido al de 1915-1916. Algunos jefes eran nuevos, otros repetían. Ahora dirigían las tropas Eduardo C. García, Francisco R. Manzo, Alejandro Mange, Antonio Ancheta, Arnulfo R. Gómez..$^{62}$ La diferencia es que en esta ocasión no sólo hubo grandes batallas en la sierra, sino también combates en poblaciones y estaciones cercanas al río o en la ruta del norte. Uno de los más reñidos se produjo en Suaqui Grande, donde una partida de 400 yaquis se enfrentó a los defensores del poblado durante tres días de octubre de 1917. Al final, derrotados, se fueron rumbo a la sierra, dejando a sus muertos sobre el terreno. Por la parte de los defensores, murieron el coronel Antonio Ancheta y más de 20 soldados. ${ }^{63}$

Era claro que la violencia y la saña de esta guerra habían entrado en una especie de espiral inflacionaria, y que no se respetaría a nadie, civil, niño o mujer. Tal vez por eso entre los propios yaquis aliados del ejército empezaron a aparecer signos de malestar y descontento. En octubre de 1917 los que estaban asentados en Pótam, bajo el mando del teniente

${ }^{61}$ Figueroa, “La revolución”, p. 373; Macías, Vida y temperamento, p. 228, y MaYa, Los movimientos, p. 10.

${ }^{62}$ Diversas solicitudes de Calles al Secretario de Guerra, de septiembre de 1917, en FAPECyFT, Elías Calles, exp. 1-65/133 y Calles a Cárdenas, 30 de agosto de 1917, en FAPECyFT, Presidente, exp. 1.

63 Telegramas entre José Agustín Castro y Calles, del 22 al 24 de octubre de 1917, en FAPECyFT, Elías Calles, serie 202, exp. 45. 
coronel Pablo Matus, pasaron de "renuentes para obedecer órdenes del gobierno" a la rebelión. ${ }^{64}$ Igual que las demás partidas, ésta se fue al monte. El año siguiente, a fines de agosto, aceptó bajar nuevamente a Pótam, para rendirse. Pero las negociaciones fueron infructuosas y terminaron en un combate. ${ }^{65}$

Durante 1918 y 1919 menudearon las acciones de esa guerra pequeña, móvil, desesperante. Si bien los yaquis perdían las grandes batallas, siempre encontraban la manera de huir y continuaban la lucha en partidas autónomas, sobre un enemigo que empezaba a desesperarse, y en un territorio que cada vez se ampliaba más. Las quejas por robos y asesinatos menudeaban, así como las solicitudes de auxilio, tropas y armas. ${ }^{66}$ Uno de los episodios más dramáticos tuvo lugar el 2 de enero de 1918, cuando Sibalaume y su gente atacaron y descarrilaron el tren a la altura de Agua Salada. Aparentemente sólo se proponían robar a los pasajeros, pero al encontrar la resistencia de algunos militares y civiles de a bordo, y ver que algunos de los suyos morían, asesinaron prácticamente a todos los pasajeros. El maquinista había logrado, mientras tanto, huir en busca de auxilio, pero las tropas no llegaron sino hasta el día siguiente. ${ }^{67}$

${ }^{64}$ Calles a Manzo, 12 de octubre de 1917, y Calles a Levelier, 18 de octubre de 1917, ambos en FAPECyFT, Elías Calles, serie 202, exps. 91 y 95. ${ }^{65}$ Presidente Municipal de Pótam a Gobernador, 6 de septiembre de 1918, en AGES, t. 3253.

${ }^{66}$ Gran cantidad de comunicados de este tipo en AGES, t. 3253; y en AHRE, exp. 16-28-49. Pueden verse también las notas de El Universal (5 sep. 1918, 21 ene. y 6 nov. 1919) en MaYa, Los movimientos, pp. 37, 41 y 63 .

${ }^{67}$ Moncada, Me llamo Empalme, pp. 28-29. 
Ante la andanada de quejas, el gobernador Calles terminó por impacientarse, ya que no todos los ayuntamientos habían atendido las disposiciones (4 de diciembre de 1917 y 29 de enero de 1918) de formar guardias o guerrillas en cada pueblo o ciudad, que serían "auxiliares en la campaña contra los yaquis o contra cualquiera otra clase de bandidos, para la protección de sus respectivas poblaciones y para la persecución de los mencionados yaquis y bandoleros" en su jurisdicción. ${ }^{68}$

También es cierto que, como hemos visto, en el caso de ataques a las poblaciones, muchos civiles contribuyeron a su defensa y hubo quienes aportaron de buen grado su cuota, armas y caballos a la campaña. Importa acentuar esto no sólo para mostrar la existencia de una sociedad movilizada y consciente del peligro yaqui, sino porque se trata de la actualización de una tradición militarista colectiva muy propia de la cultura norteña sonorense. Finalmente, su aislamiento y su carácter fronterizo habían obligado a los sonorenses a vivir con las armas en la mano para dirimir sus disputas internas en el siglo XIX, para enfrentar diversas amenazas externas (invasiones extranjeras y de apaches) y para dominar al enemigo interno (ópatas, mayos, yaquis). ${ }^{69}$

Sin embargo, el esfuerzo de guerra comenzaba a pesar en una sociedad que apenas se recuperaba de los años revolucionarios. Muchos de los voluntarios se tomaban descansos para atender sus siembras, de modo que en 1919 fue perceptible un descenso en los ánimos guerreros. Ante la

${ }^{68}$ Circulares del Gobernador a los presidentes municipales, 4 de diciembre de 1917 y 29 de enero de 1918, en AGES, t. 3254.

${ }^{69}$ S Picer, Los yaquis, p. 171; Aguilar Camín, "Los jefes”, y Carr, "Las peculiaridades". 
imposibilidad de acabar con el enemigo, cada vez había más resistencia a prestar servicios o ayuda; además, en ocasiones el reclutamiento no era precisamente voluntario. Por otra parte, los pertrechos eran insuficientes, de modo que en muchas poblaciones se formaban guerrillas, pero no tenían armas. ${ }^{70}$

A pesar de los esfuerzos de los revolucionarios en el poder, tras tres años de guerra, las diferentes partidas yaquis seguían haciendo estragos en distintos lugares. Y en ocasiones, se cuidaban de explicar sus actos. Así, luego de un ataque a un rancho cercano a Moctezuma, cuando liberaron al dueño, Jesús F. Montaño, le dejaron un papel sin firma en el que decían:

[...] pues señores mexicanos con todos ustedes que tienen propiedades que los prejuicios causados sobrevienen del carrancismo y demás jefes revolucionarios y es principalmente el autor porque nos han desterrado de nuestros pueblos por la fuerza bruta, nosotros no quisiéramos perjudicar a ustedes, pero el gobierno nos obliga. ${ }^{71}$

En esas condiciones llegó De la Huerta a la gubernatura en septiembre de 1919, e impulsó de nuevo unas negociaciones de paz.

A mediados de enero de 1920, sus enviados, Ramón B. Armenta y Pomposo Matus, tuvieron conversaciones con

\footnotetext{
70 Presidente Municipal de Movas a Gobernador, 22 de abril de 1919, en AGES, t. 3389; Presidente Municipal de Querobabi a Gobernador, s/f; y diversos comunicados más en AGES, t. 3327.

${ }^{71}$ La carta está transcrita en Presidente Municipal de Moctezuma a Gobernador, 5 de noviembre de 1919, en AGES, t. 3389.
} 
Ignacio Mori en Estación Oroz. En ellas, Armenta les manifestó los deseos del gobernador de que "depusieran las armas y se dedicaran honradamente a trabajar siendo ayudados por el Gobierno del estado en todo lo necesario". Además, les pidió no desconfiar de este gobierno, pues se trataba de uno con "ideas socialistas" y "emanado del pueblo obrero" y que, de hecho, él mismo, Armenta, "era un obrero que les hablaba con franqueza”. Mori, por su parte, explicó que no podía tomar decisiones, y no podía viajar a Hermosillo puesto que no tenía facultades de "sus Jefes Mayores". Él únicamente era "un subalterno que venía a conferenciar con el C. Gobernador".

Uno de los puntos delicados de estas pláticas fue el asunto de las familias yaquis prisioneras. Al ser interrogado al respecto, Armenta les aseguró que "estaban perfectamente bien vestidas y bien comidas" en Hermosillo, lo que alegró mucho a Mori y los suyos. ${ }^{72}$

Finalmente Mori recibió la anuencia de los jefes "mayores", aceptó concentrar sus tropas en la Estación Oroz y llegar a algunos acuerdos. Aparentemente, el gobierno accedió a darles tierras y provisiones y el propio Mori fue con 450 hombres a recoger a las familias prisioneras en Hermosillo en la segunda semana de febrero. Según De la Huerta, aquí se presentó una diferencia entre él y Carranza, pues éste pretendía dotarles de tierra en otra entidad del país, cosa que juzgaba, acertadamente, suficiente para el fracaso de los tratados. Como explicaba en su informe de gobierno,

72 Testimonio de Armenta sobre negociaciones, Pilares de Nacozari, 20 de agosto de 1928, en AGES, t. 72 de 1927. Vale la pena señalar que mi búsqueda de las actas de estas negociaciones en los archivos fue infructuosa. 
eso contradecía el conocimiento "sociológico" de la tribu, la que "además de ser conocida en su obstinación en hacer tal o cual cosa, no se avendría fácilmente a abandonar su pequeña patria, en vía de concesión en los tratados, que tal vez no comprendería a fondo y por lo mismo desconfiaría de ellos". ${ }^{73}$

Como quiera que sea, el precario acuerdo encontró un refuerzo en los acontecimientos que condujeron a la rebelión de Agua Prieta en abril y mayo de 1920. En una jugada decisiva, De la Huerta envió a Fructuoso Méndez (sacado al efecto del ostracismo político en que estaba por su pasado villista) a tratar de concertar una alianza con el general Mori en esta nueva aventura. Los enviados - pues iban también el capitán Marcelo Zavala y seguramente Pomposo Matus - fueron recibidos en el cañón del Guapari por los gobernadores de los pueblos, quienes aceptaron la alianza. Bajaría a Oroz la mayor cantidad de indios armados que se pudiera, y 50 yaquis escogidos formarían una escolta personal de De la Huerta hasta México, bajo el mando directo de un yaqui llamado Francisco Flores. Además, se desocuparían los pueblos y se construirían escuelas e iglesias. Los acuerdos, según Zavala, fueron puestos por escrito y enviados a Hermosillo, bien guardados en los pechos de una emisaria yaqui, "entrada en años y en carnes", para la firma del gobernador (pero en 1924 no había rastro de ellos en los archivos y el secretario de Gobierno afirmaba que habían sido verbales). Una semana después

73 Citado en Dabdoub, Historia, p. 209. 
[...] los indios broncos empezaron a bajar de la sierra en gran número a formar campamentos en Estación Oroz. Llegaban en grandes partidas, llevando a sus mujeres y ocupándose inmediatamente de levantar ramadas, mientras las mujeres encendían hogueras para sus comidas. Venían mal vestidos, pero perfectamente armados y municionados, constituyendo un contingente de dos mil quinientos combatientes. ${ }^{74}$

Resulta difícil no asombrarse de esa cifra de 2500 combatientes, manejada por Marcelo Zavala, entonces capitán y testigo presencial del episodio. Pero saca a la luz, de manera vívida, lo que para De la Huerta parecía claro. Después de cuatro años de guerra, su capacidad de lucha, resistencia y recuperación estaba ahí plasmada, viva, en ese pueblo yaqui reunido en Oroz.

Como sabemos, el triunfo de los rebeldes de Agua Prieta fue bastante rápido y con ello De la Huerta se convirtió en presidente provisional de México por seis meses. Al principio tuvo como guardia presidencial al grupo de yaquis que lo escoltaron hasta la Ciudad de México, pero éstos no resistieron mucho tiempo lejos de sus tierras. Igualmente, tuvo como invitado en la Ciudad de México a Ignacio Mori, a mediados de junio de 1920. En todo caso, los jefes yaquis comenzaron a recibir ayudas en efectivo del gobierno, así como provisiones, pero no hubo intento de retirar de los pueblos a las tropas o a los blancos. Y aun cuando se permitió a algunos yaquis regresar a sus pueblos, también es verdad que en los años siguientes hubo una deportación

\footnotetext{
74 Zavala citado en Dabdoub, Historia, p. 217. Véase también MurrieTA y Graf, Por el milagro, pp. 181-183.
} 
"disfrazada" de muchos, al enrolarlos no del todo voluntariamente en el nuevo ejército federal. ${ }^{75}$

La paz que se consiguió con ello fue relativa y precaria. Entre los muchos incidentes posteriores estuvieron el ataque y destrucción del palacio municipal de Pótam en julio de $1921,{ }^{76}$ así como algunos robos y asesinatos en el camino de Bácum a Cócorit en mayo de 1922.

$\mathrm{Al}$ denunciar estos hechos, los vecinos de Bácum hacían ver que, a pesar de la presencia militar en el valle, muchos yaquis no parecían dispuestos a cejar en su rechazo a la dominación mexicana. Más aún, no se comportaban como derrotados. Según estos vecinos:

Ellos están armados y perfectamente municionados y no olvidan ni dejan de poner en práctica demostraciones hostiles que nos tienen en continua tensión y alarma, pues tampoco abandonan su aire y actitud altanera hacia los de la raza blanca; mientras que nosotros nos encontramos casi fuera de acción, ya que no disponemos de las fuerzas o armas y parque necesarios para hacernos respetar y, sobre todo, por el hecho de encontrarnos a muchos kilómetros de distancia de los cuarteles de las tropas federales, que pudieran auxiliarnos o, mejor dicho, salvarnos en un caso dado. ${ }^{77}$

75 José de la Luz Armenta a Gobernador, 3 de mayo de 1920 y 25 de junio de 1920; Luis Matus a Gobernador, 27 de mayo de 1920; y J. C. Bustamante, gobernador provisional de Sonora a Presidente De La Huerta, 8 de junio de 1920, todos en AGES, t. 3389, primera parte. Véanse también Ramírez, La participación, p. 97 y ss., y Rivera, La revolución, pp. 508-510.

${ }_{76}$ Francisco S. Elías a Presidente de la República, 4 de julio de 1921, en AGN, Obregón-Calles, exp. 101-Y-2.

77 Vecinos de Bácum a Presidente de los Estados Unidos Mexicanos, 31 de mayo de 1922, en AGN, Obregón-Calles, exp. 101-Y-2. 
Muchos años después, en 1943, Ángel Bassols recogió un testimonio parecido del capitán Felipe, que había pasado ocho años a salto de mata en la sierra, peleando contra los blancos. Le dijo: "Nos querían quitar el río, los yoris. Y contra ellos pusimos el pecho y apuntamos el máuser. Y no nos vencieron". ${ }^{78}$

\section{CONCLUSIONES}

El verdadero fondo del problema es que se trataba de una campaña que sólo podía ganarse a la larga, y con enormes recursos no sólo de la federación, sino del propio estado. En cambio, las derrotas, los muertos, los presos y las familias de nuevo desmembradas u orilladas a vivir en la sierra, a salto de mata, no bastaron para rendir a una parte del pueblo yaqui. Era como si el sentido total de su lucha estuviera representado por el territorio heredado, encomendado tanto por los dioses como por los antepasados. Por eso, fue necesario que Calles y Obregón, ya en la cima del poder nacional, hicieran una nueva guerra contra ellos entre 1926 y 1929, tan cruenta como la que hemos relatado aquí. Y aun después de ella, aunque esporádicos, hubo actos de rebelión yaqui, prácticamente hasta que convinieron una paz más duradera con Lázaro Cárdenas.

Una de las claves para entender esto es aquello que ya sugería Aguilar Camín. En lo que toca a la cuestión yaqui, es posible afirmar una notable continuidad en las políticas del Estado mexicano del porfiriato a la Revolución. Ciertamente Madero, tal vez Obregón, Estrada, De la Huerta

${ }^{78}$ Bassols, El Noroeste, p. 26. 
y otros líderes, estuvieran animados de buenas intenciones hacia ellos, pero igual que Díaz habían tenido que hacerlas a un lado, en tanto no podían concederles aquello que más les importaba: la salida de los colonos blancos y del ejército de sus tierras. El propio Porfirio Díaz, todavía en 1886, no aceptó la idea de deportación, pues hubiera significado iniciar una "guerra de exterminio", ya que como los indios "preferían la muerte al exilio", pelearían por su tierra hasta la muerte. Aunque en ese momento le había bastado con enrolar a los líderes en el ejército como medida intermedia, después aceptó como inevitable la deportación y el exterminio. ${ }^{79}$ Como hemos visto aquí, los revolucionarios también tuvieron que cambiar sus opiniones al encontrarse con que buena parte del pueblo yaqui no aceptaba sus propuestas de dividir la tierra, de mantener sus proyectos de colonización y modernización agrícola y, sobre todo, de subordinarlos a su proyecto civilizatorio. ${ }^{80}$

Creo que a esas alturas no tenían la posibilidad de entenderse unos a otros. Había corrido tanta sangre en los años anteriores que el recelo y la desconfianza eran mutuos. Por lo demás, siempre es útil recordar que en la sociedad yaqui el individualismo tenía un lugar bastante más pequeño que en la mexicana. Los destinos individuales estaban supeditados al destino colectivo en una medida que no es concebible para los que estaban del otro lado, en el lado occidental. Pero, al mismo tiempo, los años de la guerra habían tenido como consecuencia la descentralización de la sociedad yaqui. No había un centro director de la misma,

${ }_{79}$ Hu-DeHart, Yaqui Resistance, p. 113.
80 Véase Bonfil, México profundo, pp. 156-160. 
aun cuando pueda defenderse la existencia de una especie de conciencia e identidad grupal. Por eso, si bien era complicado tomar y mantener cualquier decisión o acuerdo de paz, era imposible decir que una victoria sobre alguna de sus partidas, por importante que fuera, significara acercarse a una victoria final sobre los rebeldes.

Tal vez la consecuencia más importante de esta larga y cruenta guerra fue el ahondamiento de la brecha cultural simbólica que separaba a los mexicanos y a los yaquis, al menos en su parte más rebelde. Calles, siempre poco delicado en estas cuestiones, abiertamente dejaba de lado toda la retórica populista revolucionaria para fijar la postura de su gobierno en su manifiesto al pueblo de Sonora de octubre de 1917. Ahí expresaba que no era posible que "un puñado de salvajes" mantuviera a raya a un pueblo "civilizado, laborioso y viril" como el de Sonora y los amenazaba con el "exterminio", si ello "fuera necesario". En privado - como confiaba al coronel Jesús $\mathrm{O}$. Cota-, incluso se decía decepcionado de esa tribu, puesto que a su "idealismo" revolucionario, a los esfuerzos humanitarios de regenerarla mediante el trabajo y la instrucción, habían respondido con "la más negra de las ingratitudes", ya que "toda la tribu se ha rebelado". Como hombre "radical" en sus procedimientos, explicaba, "ahora la campaña será la muerte para ellos". ${ }^{81}$

Del lado yaqui, las cosas no se veían mejor. En un manifiesto dirigido "A los habitantes de esta región”, probablemente de febrero de 1918, algunos jefes militares yaquis se lamentaban de "las vidas que inocentemente se pierden por

${ }^{81}$ Macías, Vida y temperamento, p. 228; y Calles a Cota, Agua Prieta, 9 de nov. de 1917, en FAPECyFT, Elías Calles, serie 202, exp. 53. 
el capricho de unos cuantos hombres ambiciosos que piensan sostener la desolación y muerte de todos los hijos de la República, hombres sin un ápice de conciencia ni respeto a las leyes humanas". Como "el Gobierno, movido por los hacendados y los americanos, quería exterminar nuestra raza", tenían "la necesidad de hacer daño por todas partes". El Gobierno se quejaba de las vidas perdidas en el descarrilamiento del tren de enero, pero su escolta "tirotea constantemente a nuestra gente cuando ella cruza la vía". En fin, mientras siguiera el "atropello contra nuestra tribu la mortandad será más terrible”.

Este manifiesto es interesante porque intenta contrarrestar el rechazo a sus acciones, proponiendo a "los pobres" no yaquis, también oprimidos por el Gobierno, una alianza que, por lo demás, tenía precedentes en su historia. Decían:

Mientras el Gobierno siga vendiendo nuestra raza a los hacendados de Yucatán como lo hizo Rafael Izábal e insista en no entregar nuestras tierras, la lucha seguirá dura y encarnizada. Los hombres que llevan a la fuerza el Gobierno es culpable y a él deben castigarle. Nosotros queremos únicamente arreglos con toda la gente pobre que vive de su trabajo honrado y honesto fuera del gobierno, como antes, en el tiempo de Refugio Tánori, mandaba la pimería y otros jefes de los pápagos y ópatas, en aquellos tiempos esas gentes nos respetaban y nos ayudaban a abatir a los invasores de nuestros ríos, hasta el río Mayo y nosotros también hacíamos lo mismo[...]. ${ }^{82}$

${ }^{82}$ Julián Cosari, Manuel Periat, Victoriano Azul e Ignacio Ipachola, "Manifiesto a los habitantes de esta región", febrero de 1918, en AGES, t. 3253 . 
Pero el tiempo occidental había cambiado mucho las cosas y no había lugar para una nueva alianza de los pobres. Los ópatas y los pimas bajos prácticamente habían sido integrados a los pueblos y ciudades de Sonora, y los pápagos, aunque defendían su modo de vida tradicional y conservaron la posesión de su territorio, también "se integraban al desarrollo económico del Estado como agricultores y ganaderos en pequeña escala y como trabajadores asalariados (vaqueros, peones agrícolas y mineros)" ${ }^{83}$ Finalmente, los revolucionarios, a la vez que combatían a los yaquis, habían logrado ganarse la lealtad de muchos de los nuevos pobres del país y de Sonora. Y con ello fortalecieron su proyecto de desarrollo, que no incluía la autonomía de los yaquis en Sonora. Peor aún, muchos de los yaquis, después de tanta guerra y privaciones, tal vez no veían otra alternativa que la integración en la sociedad mexicana.

\section{SIGLAS Y REFERENCIAS}

AGES Archivo General del Estado de Sonora, México.

AGN Archivo General de la Nación, Ciudad de México.

AHDN Archivo Histórico de la Defensa Nacional, Ciudad de México.

AHRE Archivo Histórico de la Secretaría de Relaciones Exteriores, Ciudad de México.

FAPECyFT Fideicomiso Archivos Plutarco Elías Calles y Fernando Torreblanca, Ciudad de México.

Acuña, Rodolfo

Caudillo sonorense: Ignacio Pesqueira y su tiempo, México, Era, 1981.

${ }^{83}$ Figueroa, "La revolución mexicana”, p. 362. 
Aguilar Camín, Héctor

La frontera nómada: Sonora y la Revolución Mexicana, México, Siglo Veintiuno editores, 1981.

"Los jefes sonorenses de la Revolución Mexicana", en AguiLAR CAMÍn, 1982, pp. 15-56.

Saldos de la Revolución. Cultura y política de México, 19101980, México, Nueva Imagen, 1982.

Alarcón Menchaca, Laura

José María Maytorena. Una biografía política, Zapopan, Jalisco, El Colegio de Jalisco, El Colegio de Sonora, Universidad Iberoamericana, 2008.

Almada, Ignacio

Breve historia de Sonora, México, Fondo de Cultura Económica, 2000.

Almada, Francisco R.

Diccionario de Historia, geografía y biografía sonorenses, México, Instituto Sonorense de Cultura, 2009.

La Revolución en el estado de Sonora, México, Instituto Nacional de Estudios Históricos sobre la Revolución Mexicana, 1971.

Balbás, Manuel y Fortunato Hernández

Crónicas de la Guerra del Yaqui, Hermosillo, Gobierno del Estado de Sonora, 1985.

Bassols Batalla, Ángel

El Noroeste de México. Un estudio geográfico económico, México, Universidad Nacional Autónoma de México, 1972.

Bojórquez, Juan de Dios

Forjadores de la Revolución mexicana, México, Instituto Nacional de Estudios Históricos sobre la Revolución Mexicana, 1960. 
Bonfil Batalla, Guillermo

México profundo. Una civilización negada, México, De Bolsillo, 2010.

Breceda, Alfredo

México revolucionario, México, Instituto Nacional de Estudios Históricos sobre la Revolución Mexicana, 1985, t. II.

CARr, Barry

"Las peculiaridades del norte mexicano, 1880-1927: ensayo de interpretación”, en Historia Mexicana, xxII: 3 (87) (ene.-mar. 1973), pp. 320-346.

Corral, Ramón “José María Leyva Cajeme”, en Corral, 1959, pp. 149-192. Obras históricas, Hermosillo, Instituto Nacional de Antropología e Historia, 1959.

Cuevas Arámburu, Mario (comp.)

Sonora. Textos de su historia, México, Instituto de Investigaciones Dr. José María Luis Mora, 1989, t. 3.

Cumberland, Charles C.

Madero y la revolución mexicana, México, Siglo Veintiuno editores, 1997.

Dabdoub, Claudio

Historia de El Valle del Yaqui, México, Porrúa, 1964.

Fabila Montes de Oca, Alfonso

Las tribus yaquis de Sonora. Su cultura y anhelada autodeterminación, México, Secretaría de Educación Pública, 1945.

Figueroa Valenzuela, Alejandro

"La revolución mexicana y los indios de Sonora”, en RADDING (coord.), 1997, pp. 353-378. 
Grajeda Bustamante, Aarón (comp.)

Seis expulsiones y un adiós. Despojos y exclusiones en Sonora, México, Universidad de Sonora, Plaza y Valdés, 2003.

Henderson, Peter V. N.

"Un gobernador maderista: José María Maytorena y la Revolución en Sonora”, en Historia Mexicana, LI:1 (201) (jul.-sep. 2001), pp. 151-185.

Hernández Silva, Héctor C.

Insurgencia y autonomía. Historia de los pueblos yaquis: 18211910, México, Centro de Investigaciones y Estudios Superiores en Antropología Social, 1996.

Holden Kelley, Jane

Mujeres yaquis. Cuatro biografías contemporáneas, México, Fondo de Cultura Económica, 1982.

Hu-De Hart, Evelyn

"Development and Rural Rebellion: Pacification of the Yaquis in the Late Porfiriato", en The Hispanic American Historical Review, 54: 1 (1974), pp. 72-93.

Yaqui Resistance and Survival. The Struggle for Land and Autonomy 1821-1910, Madison, University of Wisconsin Press, 1984.

"Rebelión campesina en el noroeste: los indios yaquis de Sonora, 1740-1976”, en KAтZ (comp.), 1990, pp. 135-163.

Adaptación y resistencia en el Yaquimi. Los yaquis durante la Colonia, México, Centro de Investigaciones y Estudios Superiores en Antropología Social, 1995.

"Solución final: la expulsión de los yaquis de su Sonora natal", en Grajeda (comp.), 2003, pp. 133-167.

Huerta, Adolfo de la

Memorias, Hermosillo, Gobierno del Estado de Sonora, 1981. 
KATZ, Friedrich

Pancho Villa, México, Era, 1998.

Revuelta, rebelión y revolución. La lucha rural en México del siglo XVI al siglo XX, México, Era, 1990, t. I.

Macías Richards, Carlos

Vida y temperamento. Plutarco Elías Calles, 1877-1920, México, Fondo de Cultura Económica, 1995.

Madero, Francisco I.

La sucesión presidencial en 1910, México, Colofón, 2006.

Maya Nava, Alfonso

Los movimientos armados en México 1917-1994, México, El Universal, 1994, t. 1.

Moctezuma Zamarrón, José Luis

De pascolas y venados. Adaptación, cambio y resistencia de las lenguas yaqui y mayo frente al español, México, Siglo Veintiuno editores, 2001.

Moncada, Carlos

Me llamo Empalme, Hermosillo, Sonora, Latinoamericana, 1988.

Murrieta, Mayo y Eugenia Graf

Por el milagro de aferrarse. Tierra y vecindad en el Valle del Yaqui, México, Seminario de Historia Oral Mexicana, 2012.

Obregón, Álvaro

Ocho mil kilómetros en campaña, México, Fondo de Cultura Económica, 1973.

OKada, Atsumi

"El impacto de la Revolución Mexicana: la Compañía Constructora Richardson en el valle del Yaqui, 1905-1928”, en Historia Mexicana, L:1 (197) (jul.-sep. 2000), pp. 91-143. 
Olavarría, María E.

Cruces, flores y serpientes. Simbolismo y vida ritual yaquis, México, Universidad Autónoma Metropolitana, 2003.

Padilla Ramos, Raquel

Yucatán: fin del sueño yaqui, el tráfico de los yaquis y el otro triunvirato, Hermosillo, Gobierno del Estado de Sonora, 1995.

Radding, Cynthia (coord.)

Sonora moderno: 1880-1929, t. IV de Historia general de Sonora, Hermosillo, Gobierno del Estado de Sonora, 1997.

Ramírez Zavala, Ana Luz

La participación de los yaquis en la revolución 1913-1920, Hermosillo, Sonora, Instituto Sonorense de Cultura, 2009.

Rivera, Antonio G.

La revolución en Sonora, México, s. e., 1969.

Ruiz Ruiz, Ma. Trinidad (comp.)

Tres procesos de lucha por la sobrevivencia de la tribu yaqui, Hermosillo, Programa de Apoyo a las Culturas Municipales y Comunitarias, 1994.

Schutz, Alfred

Estudios sobre teoría social. Escritos II, Buenos Aires, Amorrortu, 2003.

Spicer, Edward H.

"Eventos fundamentales de la historia yaqui", en Cuevas (comp.), 1989, pp. 246-258.

Los yaquis. Historia de una cultura, México, Universidad Nacional Autónoma de México, 1994. 
SuÁrez del Solar, María de los Ángeles (comp.)

Francisco I. Madero. Antología, México, Instituto Nacional de Estudios Históricos sobre la Revolución Mexicana, Archivo General de la Nación, 1987.

Taibo II, Paco Ignacio

Yaquis. Historia de una guerra popular y de un genocidio en México, México, Planeta, 2013.

Taracena, Alfonso

La verdadera Revolución Mexicana (1901-1911), México, Porrúa, 2005.

TAylor, Lawrence Douglas

La gran aventura en México: el papel de los voluntarios extranjeros en los ejércitos revolucionarios mexicanos, 1910-1915, México, Conaculta, 1993, t. I.

Troncoso, Francisco P.

Las guerras con las tribus yaqui y mayo del estado de Sonora, México, Secretaría de la Defensa Nacional, 1984.

Zavala Castro, Palemón

El indio Tetabiate y la nación de los Ocho Pueblos del Río Yaqui, Hermosillo, Gobierno del Estado de Sonora, 1991. 
